Illinois State University

ISU ReD: Research and eData

Theses and Dissertations

7-3-2014

\title{
More Than A Personality Match? High School Administrator Views On The Process, Factors Relevant, And Effectiveness Of The Selection Of Cooperating Teachers
}

Julie Lickfelt Pavlini

Illinois State University, juliepavlini@yahoo.com

Follow this and additional works at: https://ir.library.illinoisstate.edu/etd

Part of the Elementary and Middle and Secondary Education Administration Commons, and the Secondary Education and Teaching Commons

\section{Recommended Citation}

Pavlini, Julie Lickfelt, "More Than A Personality Match? High School Administrator Views On The Process, Factors Relevant, And Effectiveness Of The Selection Of Cooperating Teachers" (2014). Theses and Dissertations. 238.

https://ir.library.illinoisstate.edu/etd/238

This Dissertation is brought to you for free and open access by ISU ReD: Research and eData. It has been accepted for inclusion in Theses and Dissertations by an authorized administrator of ISU ReD: Research and eData. For more information, please contact ISUReD@ilstu.edu. 


\title{
MORE THAN A PERSONALITY MATCH? HIGH SCHOOL ADMINISTRATOR VIEWS ON THE PROCESS, FACTORS RELEVANT, AND EFFECTIVENESS OF THE SELECTION OF COOPERATING TEACHERS
}

\author{
Julie L. Pavlini
}

133 Pages

December 2014

The purpose of this study was to describe the factors perceived relevant to high school administrators in selecting cooperating teachers in English, math, and science. Qualitative research techniques were used; themes from the data were organized by the research questions and analyzed through the conceptual framework of Charlotte Danielson's (2007) Framework for Effective Teaching. This study included semistructured interview probes and two activity components.

All five participants were complimentary of their school's cooperating teacher selection process and identified several traits and factors as important in selecting cooperating teachers: commitment to professional development and continuous learning, enthusiasm for teaching, varied but not advanced placement teaching assignments, several years of experience, and match of personal preferences and interests of the cooperating teacher and student teacher. A strong teacher evaluation rating also was mentioned as valuable, but little detailed evidence during the interviews confirmed this assertion. When identifying important traits from the specific elements provided from 
Danielson's (2007) Framework for Effective Teaching, participants most often selected the use of formative and summative assessment to guide instruction and reflection on teaching practices as preferred traits. The traits identified as most important were not consistently expressed in the interview probe responses and the activity components, suggesting traits verbalized as important were not necessarily applied as important in the cooperating teacher selection process.

The findings of this study provide important implications for school administrators and university partners in specifically determining the qualifications for cooperating teachers and evaluating the effectiveness of cooperating teachers. 
MORE THAN A PERSONALITY MATCH? HIGH SCHOOL ADMINISTRATOR VIEWS ON THE PROCESS, FACTORS RELEVANT, AND EFFECTIVENESS OF THE SELECTION OF COOPERATING TEACHERS

JULIE L. PAVLINI

A Dissertation Submitted in Partial Fulfillment of the Requirements for the Degree of DOCTOR OF EDUCATION

Department of Educational Administration and Foundations

ILLINOIS STATE UNIVERSITY 


\section{MORE THAN A PERSONALITY MATCH? HIGH SCHOOL ADMINISTRATOR VIEWS ON THE PROCESS, FACTORS RELEVANT, AND EFFECTIVENESS OF THE SELECTION OF COOPERATING TEACHERS}

JULIE L. PAVLINI

COMMITTEE MEMBERS:

Neil Sappington, Chair

Lydia Kyei-Blankson

Guy Banicki

Elizabeth Lugg 


\section{ACKNOWLEDGMENTS}

When I applied to the ISU doctoral program, my application essay reminisced about the mashed potato salad recipe that was born the day my Uncle Larry graduated with his doctorate in education. Some recipes are clear and easy to follow; other recipes, like the one for mashed potato salad, are developed as you go. Thank you to all who contributed to my recipe.

To my advisor and dissertation chair, Dr. Neil Sappington, I cannot thank you enough for believing in my topic, seeing the connection between teaching and leadership in a way that I had yet to even realize. Your counsel has been invaluable. To my methodologist Dr. Lydia Kyei-Blankson and my qualitative research professor Dr. Wendy Troxel, I am grateful for your guidance. Together, you gave me the recipe for developing a qualitative study, and then you helped me to vary that recipe, to design my own study with interactive activities that were unique. Dr. Betsy Lugg and Dr. Guy Banicki, you read my work with a critical yet supportive eye. Thank you for serving on my committee and lending your expertise to this endeavor.

I offer special thanks to my family, friends, and teachers along the way - from my roots in Ebenezer Lutheran Church and the Chicago Public Schools to the amazing experiences at Wartburg College and into the professional world. So many supporters and mentors have traveled by my side; some are now angels who watch from above. In these last few years, you gently (and sometimes not so gently) asked about classes and 
"the paper." You sacrificed when I had to read, write, revise and when I was just too worn out to do anything else. I am grateful for your support and encouragement.

Most importantly, I wish to dedicate this work to my husband and best friend, Tommy. He was there every step of the way: from the sleepless nights to the jubilation over each finished page, from the tears of frustration to the tears of joy and accomplishment. T, I will be forever thankful that you have always believed in me and made my dream our dream.

J. L. P. 


\section{CONTENTS}

Page

ACKNOWLEDGMENTS $\quad$ i

CONTENTS

TABLES vii

FIGURES Viii

CHAPTER

I. THE PURPOSE OF THE STUDY AND ITS CLARIFYING COMPONENTS 1

Overview 1

Evolving Role of the Teacher 3

Statement of the Problem 9

Definitions and Technical Terminology 13

Conceptual Framework 14

Research Questions $\quad 16$

$\begin{array}{ll}\text { Study Design } & 18\end{array}$

Sample Selection $\quad 18$

Data Sources and Data Collection $\quad 19$

Data Analysis $\quad 20$

$\begin{array}{ll}\text { Assumptions } & 21\end{array}$

Delimitations $\quad 21$

Limitations to the Study $\quad 22$

Organization of the Study $\quad 22$

II. REVIEW OF LITERATURE 23

Introduction 23

Importance of Teacher in Pupil Achievement 24

Normal School Teachers vs. Highly Qualified Teachers 24

Measuring Effectiveness: Design of Danielson's Framework 27 
Impact of Signature Pedagogy of Teacher Development

Value of Signature Pedagogy

Signature Pedagogy for Teaching

Areas and forms of knowledge

Contexts for teacher training

Culture of Isolation

Teacher Preparation Connects to Pupil Learning

Teacher Preparation Connects to Future Teaching Success

Role of Cooperating Teacher in Student Teaching Placement 44

Importance of the Student Teaching Experience 47

Training and Certification Program Expectations 61

Support for the triad 61

Partnerships with schools $\quad 62$

$\begin{array}{ll}\text { Summary } & 64\end{array}$

III. METHODOLOGY OF THE STUDY 65

Research Questions $\quad 65$

Research Procedures $\quad 66$

Research Ethics $\quad 68$

Qualitative Techniques $\quad 68$

Research Positionality and Reflexivity 73

Data Analysis $\quad 74$

Ensuring Reliability and Validity $\quad 75$

$\begin{array}{ll}\text { Summary } & 75\end{array}$

IV. ANALYSIS OF RESULTS

$\begin{array}{ll}\text { Introduction } & 76\end{array}$

$\begin{array}{ll}\text { Participant Profiles } & 76\end{array}$

$\begin{array}{ll}\text { Participant \#1 } & 77\end{array}$

$\begin{array}{ll}\text { Participant \#2 } & 78\end{array}$

$\begin{array}{ll}\text { Participant \#3 } & 78\end{array}$

$\begin{array}{ll}\text { Participant \#4 } & 78\end{array}$

$\begin{array}{ll}\text { Participant \#5 } & 79\end{array}$

$\begin{array}{ll}\text { School Profiles } & 79\end{array}$

$\begin{array}{ll}\text { School \#1 } & 79\end{array}$

$\begin{array}{ll}\text { School \#2 } & 79\end{array}$ 
$\begin{array}{lr}\text { Research Issue } & 80\end{array}$

$\begin{array}{ll}\text { Results } & 80\end{array}$

Research Question \#1 80

Process rather than task $\quad 81$

$\begin{array}{ll}\text { Collaborative conversation } & 82\end{array}$

Designated roles of participants 84

Importance of individual preferences and perspectives 86

$\begin{array}{ll}\text { Research Question \#2 } & 87\end{array}$

$\begin{array}{ll}\text { Experience } & 88\end{array}$

Professional development 90

$\begin{array}{ll}\text { Attitudes and beliefs } & 90\end{array}$

Research Question \#3 92

Curricular alignment $\quad 92$

Use of assessment 92

Research Question \#4 93

Role models $\quad 93$

Growth opportunity $\quad 94$

Contributing to the profession $\quad 94$

Research Question \#5 95

Evaluation ratings $\quad 96$

No evidence as evidence $\quad 96$

Comparison of the Case Study Districts $\quad 97$

Through the Lens of Danielson's Framework 100

Domain 1: Planning and Preparation 100

Domain 2: The Classroom Environment 102

Domain 3: Instruction $\quad 102$

Domain 4: Professional Responsibilities 103

$\begin{array}{ll}\text { Summary } & 104\end{array}$

V. CONCLUSIONS, IMPLICATIONS, AND RECOMMENDATIONS 106

Introduction 106

Overview of the Study 106 
$\begin{array}{ll}\text { Summary of Findings } & 108\end{array}$

Research Question \#1 108

Research Question \#2 108

Research Question \#3 109

Research Question \#4 109

Research Question \#5 110

$\begin{array}{ll}\text { Conclusions } & 110\end{array}$

Implications and Strategies 111

Qualifications for Cooperating Teachers 111

Evaluations $\quad 113$

Limitations $\quad 114$

Recommendations for Future Research 114

$\begin{array}{ll}\text { REFERENCES } & 118\end{array}$

APPENDIX A: Sample Recruitment Letter 129

APPENDIX B: Sample Consent Form 130

APPENDIX C: Interview Probes 131

APPENDIX D: Interview Activity \#1 132

APPENDIX E: Interview Activity \#2 133 


\section{TABLES}

$\begin{array}{lll}\text { Table } & \text { Page }\end{array}$

$\begin{array}{ll}\text { 1. Interview Activities } & 20\end{array}$

2. Study Schools and Participants 77

3. Choose a CT Activity Responses 97

4. Trait Sort Activity Responses-Top Ranking Traits 98

5. Trait Sort Activity Responses—Lowest Ranking Traits 99 


\section{FIGURES}

$\begin{array}{lll}\text { Figure } & \text { Page }\end{array}$

1. Balance of Knowledge in Signature Pedagogy for Teaching 38

2. Kennedy's Contexts of Teacher Training (1999) 40 


\section{CHAPTER I}

\section{THE PURPOSE OF THE STUDY AND ITS CLARIFYING COMPONENTS}

\section{Overview}

The role of the teacher has been shown as pivotal to the achievement of students. Recognition of the importance of this role has led those committed to improving education on a campaign to ensure the quality of teachers in all classrooms. With the effects of the national No Child Left Behind (NCLB) legislation seen by many as inconsistent, the determination of what makes a quality teacher is gaining more attention. The path of consequences that was set by NCLB has not consistently improved schools because it was based on assumptions (Ravitch, 2010), so now a new path focused on teacher quality has been set. This new path links student achievement to teacher evaluation, with teacher employment becoming more dependent on evaluation than archaic tenure rights.

The Illinois Performance Evaluation Reform Act (PERA) was signed into effect in 2010 and raised the expectations for educators. The act requires Illinois school districts to include a research-based professional framework as part of their evaluation tool. According to research cited in the reform act, student growth was most significant for those who were taught by teachers who scored highest on the frameworks. With the evaluation of teachers and administrators impacted by student achievement data, efforts to improve teacher quality are being redoubled (http://www.isbe.net/news/2011/nov18. htm). 
Due to various issues, such as limited financial supports in schools as a result of funding issues in Illinois, the professional development provided to teachers to help them improve in quality once they are staff members varies from district to district, and not necessarily in positive ways. In addition to the concern surrounding the disparity in professional development opportunities across districts, research conducted by Sappington, Pacha, Baker, and Gardner (2012), using 106 schools in Illinois, shows that professional development remains separated from school improvement efforts in many schools. These limitations have strong implications for pre-service teacher training. Ensuring teacher quality during the teacher preparation stage has therefore become much more important.

Work of the American Association of Colleges for Teacher Education (2011) highlights the need for teachers to be well prepared to effect true improvement in student learning, noting "the need to strengthen educator preparation and the accountability of its programs is vital to ensuring that students are career- and college-ready when they graduate from high school" (p. 14). With such a focus, student teaching placement appears to be one of the most critical transitions for teachers as they move from the college and university preparation stage into school employment; teacher preparation is a leading factor that affects student achievement.

The roles of the student teaching triad are critical: student teacher, university supervisor, and cooperating teacher. The role of the university supervisor is the link between the life of the student teacher as he moves from student to teacher. Additionally, cooperating teachers, supervising student teachers during their pre-employment internship, are critical in this final stage of university pre-teaching preparation. 


\section{Evolving Role of the Teacher}

At this point, it is important to draw attention to the fact that the role of the teacher in school has changed over the years. In the earliest U.S. schools, the days of the one-room schoolhouses, the teacher was a "jack of all trades." Chosen for a variety of reasons, from moral status to knowledge of content, the teacher attempted to cover the basics with the students who were present for as many years as they attended, until family commitments or work pulled students away from their education. The teacher worked in isolation with little to no external supports, but the role of the teacher was respected as a sort of vocation (Lortie, 1975). The educational goals were focused on basic reading and writing, and teachers were expected to deliver instruction to all students.

Later, a demand for efficiency and the application of the scientific model awkwardly merged with education (Bobbitt, 1913). The factory model led to a more structured larger organizational framework, including the citizen governing board (Tyack, 1967), similar at least in concept to today's boards of education. Reform of this era focused on establishing a culture and structure and not on instructional improvements.

Reformers of the progressive era that followed argued that schools needed to better prepare students as problem solvers, as creative thinkers, as more than the cogs in a machine of the factory era. Choice and flexibility, as part of the problem-solver mentality, prevailed. The power of the individual prevailed. Instructional prompts to provide real life application of learning began, but these attempts were not systemic or adequately supported. The changes of this time were slow and limited, though well intentioned. As Larry Cuban (1984) identified in his study of reforms from the progressive period, the changes that were heralded as being more student centered 
"seldom appeared in more than one-fourth of the classrooms in any district that systematically tried to install these varied elements" (p. 135).

Further evidence of the limited impact of reform came in the well-known Coleman report (Coleman, Campbell, Hobson, McPartland, Mood, Weinfield, \& York, 1966). Using assessment data from a nationwide survey commissioned by the U.S. Commissioner of Education, Coleman's team argued that schools had little effect on the learning and achievement of a student. Instead, family background influences were the determining factors in one's success.

Though schools were more comprehensive by this time, it was argued that schools and, by extension, teachers were not making the grade. The 1970s saw a strong push for the return of basic skills, as supported by the research of behavior theorists. Edmonds (1979) offered a bright spot in the dark days of criticism with major contributions to the school effectiveness movement of the 1970s. As reported from his own studies and as shown in the analysis of the studies of others, Edmonds repeatedly evidences that schools, beyond family dynamics or socioeconomic status, can positively impact the success of a student.

Progressives were not eager to give up in the midst of demands for a return to core instruction, so an expectation that schools could be everything to all students emerged. The additional expectations for schools to be everything to every child opened the doors for various groups that had been underserved or completely ignored academically and socially. The picture of a clear mission was emerging; however, some would argue the increase of bureaucracy in education actually created layers between the goals of improvement and instruction (Elmore \& McLaughlin, 1983). In retrospect, these 
layers would begin decades of buffering between policy and the instructional core. These are layers that need to be peeled back.

The Coleman report's negative evaluation set a path for educational criticism that continued in the publication of A Nation at Risk in 1983. With rampant criticism and scarce resources in a difficult economy, schools were pushed to find ways to meet the four major recommendations of A Nation at Risk: increased content expectations at the high school level, adoption of higher and more demanding standards, increased time spent in core content, and significant steps to improve teacher quality (National Commission on Excellence in Education, 1983).

The standards movement was thus born and included a significant increase in access to and awareness of brain research (Jensen, 1995). In 1986 the Carnegie Foundation's report A Nation Prepared: Teachers for the $21^{\text {st }}$ Century spurred the creation of the National Board for Professional Teaching Standards (NBPTS). This cohesive movement attempted to further legitimize the complexity of the role of teachers by aligning expectations at a national level.

These new learning standards for students, though consistently popular, varied across states, and structures for the effective use of assessments to monitor the implementation of standards also varied. While the federal government continues to, even now, maintain education as a state right, with the passing of No Child Left Behind (NCLB) (2001) in the millennium, there was a new plan to bring some cohesion among assessments across the states. Though NCLB began as a pressure from above, it also can be seen as a stimulus from within. The analysis of student progress required as part of NCLB highlights the potential of all students to learn. 
In 2009, the federal government once again entered the story with an attempt to assist schools in moving forward with their instructional reform efforts. The American Recovery and Reinvestment Act (2009) included the Race to the Top contest that would prompt states to propose changes in order to access additional government funding. These changes ranged from teacher evaluation improvements to adoption of the newly created Common Core State Standards to implementing data systems that would improve the monitoring of student progress. Race to the Top tried to honor state autonomy while providing some impetus and structure for improvement across the domains of instruction and school culture, specifically focusing on the effectiveness of teachers. These efforts already begin too late, focusing on teachers who are already employed rather than building the capacity of pre-service teachers, starting them on an earlier path to effectiveness.

Student teaching is one of the main components in preparing effective teachers. Student teaching is the culminating application of content and pedagogical studies; it serves as the full-time opportunity for future professionals to apply theories and research in a true-life setting with pupils. The student teaching triad typically involves the actual student teacher, the cooperating teacher (or pair of cooperating teachers), and the university supervisor/partner. The building administrators of a given school typically put a stamp of approval on the selection of the cooperating teachers. This is peculiar in that the student teacher will be responsible for the instruction of pupils who are ultimately under this administrator's watch for 2 to 4 months. The student teaching experience, overall, must be examined, rather than only exploring the perspectives and experiences of individual student teachers. 
While many professions include a pre-employment internship, few professionals are expected to achieve the same level of independent work necessary of a first-year teacher. Though teachers are not expected to learn all they will ever need to know in their pre-service training, the "groundwork" laid during this time must be substantial (Hammerness, Darling-Hammond, Bransford, Berliner, Cochran-Smith, McDonald, \& Zeichner, 2005). While teachers can improve in effectiveness over time, their essential effectiveness must be present at the outset of their career. As a specific example, though a teacher is expected to improve each time he teaches geometry, the pupils in his first geometry class will not reap the benefits of that experience gained over time. Though part of a community of learners within the school, teaching is an isolated profession wherein teachers must begin with a certain level of effectiveness (Britzman, 1986).

Current research shows the teacher is the factor most critical to pupil success (Marzano, 2003; Tschannen-Moran, Hoy, \& Hoy, 1998; and Wright, Horn, \& Sanders, 1997). Without a proper teacher, even schools with other advantages will not be able to provide appropriate education for their pupils. Effective teachers can help students rise above the limitations of a less than stellar school (Marzano, 2003). Effective preparation of teachers ensures that a quality pool of prepared candidates is available to fill openings in schools. To prepare teachers, programs must attend to the duality of teaching as both an art and a science (Marzano, 2007), examining the contexts of all members of the student teaching triad: student teacher, cooperating teacher, and university supervisor.

The science of teaching is comprised of the components that can be taught. These components must be addressed with the current teaching population. They must also be effectively addressed in teacher preparation programs, both in the classroom instruction 
and in the required student teaching phase. The knowledge of the value of teachers has not been a constant in U.S. education (Lortie, 1975), which explains why this vital resource is not better trained and better supported in our education system.

Day-to-day contact with the student teacher is limited to the cooperating teacher. As the partner with the most direct student teacher contact, the role of the cooperating teacher is absolutely invaluable, thus making the way in which cooperating teachers are chosen critical to the quality of the teacher. Student teachers repeatedly cite their cooperating teachers as the most influential force in their pre-service teacher training (Hollins, 1995). More qualities of a student teacher are learned from a cooperating teacher than any other source, but the ways in which these qualities are learned is unclear. The roles of and expectations for those involved in the student teaching triads are also unclear. And of the three individuals involved in the triad, limited investigation has been done on the role of the administrator in the placement process, with the majority of research investigating the personality fit and affective match of the student teacher and cooperating teacher. Little attention has been paid to how the instructional skills of the cooperating teacher are monitored and transferred.

The culture of teaching evolves in response to the development of "relational trust" (Bryk \& Schneider, 2002), which is rooted in mutual understandings of expectations. The expectations are linked to individuals' and organizational beliefs, expectations, and obligations. Relational trust is fostered through open communication and transparency rather than secrecy and isolationism. Relational trust is central to the partnership triad of a student teacher. The relationship developed between the student teacher and cooperating teacher will ultimately mirror the level of trust exhibited in the 
organization, modeled and fostered by the administration and transferred when administrators identify an individual to serve as a cooperating teacher. While a number of studies exist on the broad topic of student teachers, the role of the administrator in selection of the cooperating teacher is an area of concern that requires further study and continuous investigation.

\section{Statement of the Problem}

As indicated above, a number of studies have been conducted on teacher preparedness through the student teaching experience. Most of the research, however, focuses on the perceptions of student teachers and especially perceptions regarding their relationships with their cooperating teachers. An examination of the student teaching experience from the viewpoint of an important, often tangential, partner, building and district administrators, is a missing component. Administrators' selection of cooperating teachers begins the process that will ultimately determine a teacher's success in merging the science and art of teaching. Therefore, there is a need to investigate the issue of student teaching from the perspective of administrators. This study investigated the traits high school building administrators considered most important in selecting cooperating teachers, with specific focus on how these traits aligned with Danielson's (2007) Framework for Effective Teaching. The aim was to better understand the process high school building administrators use to select the individuals who mentor, train, and support student teachers, the individuals who will be the most critical factor in the achievement of their future pupils. With the larger size of the high schools involved in this study, it was important to explore how connected administrators are to the selection of the cooperating teachers, the individuals training the future teacher candidate pool. 
This research is important because it has a direct connection to how student teachers are placed and the quality of the cooperating teachers who are charged with training the student teachers. With the large number of students currently enrolled in teaching programs in Illinois and the limited number of positions available, it is critical school districts do all that is possible to increase the likelihood that they are choosing the most talented candidates, which ties directly back to the training provided to pre-service teachers. In addition to the responsibilities in training student teachers, the transfer responsibility for preparing pupils for college and entry into the workforce is also increased at the high school level.

Rather than focusing on developing skills to improve pupil performance, the isolationist culture of teaching perpetuates the common myths that teachers are responsible for their own success and that some people are naturally good teachers while others just have to figure it out (Britzman, 1986). This negative thinking pervades the ranks of teachers to the point that the new inductees into the profession, student teachers, almost immediately feel the partnered burden of responsibility and loneliness (Britzman, 1986). Teaching is seen as a private endeavor into which outsiders, meaning anyone besides teacher and pupils, are not to interfere (Little, 1990; Lortie, 1975). "Our public schools are not normatively collective, purposeful, achievement-oriented institutions held in high regard by parents, community members, and educators themselves (Glickman, 1993, p. 19).

The culture of teaching has eroded from the once respected era of Lortie (1975). Because school is a common experience, many people feel they have the right and the expertise to be able to diagnose and prescribe improvements for schools; these 
presumptions are present in community members as well as policy makers (Ball \& Forzani, 2007). Criticism based on national and local test scores echo fallout from the Coleman Report (Coleman, Campbell, Hobson, McPartland, Mood, Weinfield, \& York, 1996). With constant pressures to improve but little resources and training to do so, it is difficult to identify exactly what changes should be measured as evidence of meaningful improvement. Some contend assessment of the overall school context as additional indicators of a school's status.

Glickman (1990) outlined significant reasons schools are not viewed as more successful, collegial institutions. The physical design of schools does not support collaboration. Most schools have little structured space prepared for teacher work that is done in groups or for classroom instruction that can be viewed and discussed in a professional manner. The individual classrooms of schools are designed to function autonomously with a focus on system efficiency rather than instructional efficacy (Callahan, 1962). Each individual classroom is outfitted identically to avoid any need for interdependence. Further, responsibility and accountability are misplaced, wherein the most veteran and presumably more talented teachers are given the more desirable and less demanding teaching assignments.

Oakes explains a school's status is also strongly affected by “access to knowledge, press for achievement, and professional conditions of teachers" (Oakes, 1989, p. 192). Though the pressures and demands are much stronger now, these indicators are interdependent and are enablers rather than causes of pupil learning. An effective model for instructional planning provides context as well as tools (Dean, Hubbell, Pitler, \& Stone, 2012). As components of a school's structure, each of these indicators can be 
controlled and, thus, improved by the intentional decision-making on the part of the school leaders in choices, e.g., professional development and resource allocation. However, this sort of cultural shift takes time, as "culture is not something that can be imposed on a social setting" (Morgan, 1986, p. 132); the culture of a school must evolve.

Monitoring growth by multifaceted internal and external gauges requires teachers to work in a more clinical way than in the past. This cultural shift is especially clear when comparing the current movement toward increased teacher accountability to the almost ethereal quality of teaching described by Lortie (1975) just half a century ago: “...the products sought by teachers... are difficult to measure by several assessment criteria....they may find the very idea [of measurement] inconsistent with respect for the individuality of children and young people" (pp. 135-136). The culture of education is not accustomed to the contemporary measurement expectations.

Teachers are typically neglected in conversations about policy and reform direction that would determine these multifaceted gauges of success. Such neglect limits teachers' professional conversations, creating an additional cultural issue.

While the literature shows the impact of student teacher placements on individuals developing a commitment to teaching and a general sense of efficacy (Knoblauch \& Woolfolk Hoy, 2008), there is a need to identify the factors that are currently considered in placing student teachers, particularly those related to the selection of cooperating teachers and how these factors contribute to effective placements where student teachers are evaluated based on student achievement. Ultimately, one's efficacy as a teacher needs to be evaluated by pupil performance rather than the self-reflection standards of decades past (Wineburg, 2006; Collier, 1999; Del Popolo, 1960). The 
cooperating teacher plays a critical role in mentoring new student teachers (Graham, 2006; Angell, 1998; Clift \& Brady, 2005; Fehn \& Koeppen, 1998; Hewson, Tabachnick, Zeichner, \& Lemberger, 1999; Koeppen, 1998; Conklin, 2009), prompting the importance of selecting the most qualified individuals to serve as cooperating teachers. With clear understanding of the factors administrators consider relevant in the selection of cooperating teachers, one of the many gaps between professional development and student learning can be closed.

\section{Definitions and Technical Terminology}

A few terms are identified here not because they are unknown to the reader but because they are used to identify particular individuals and details within the study discussion. The particular terms for the roles involved in student teaching placements were adapted from those definitions provided in the Illinois Administrative Code (2004).

Clinical student-pre-service teachers preparing to student teach.

College/university supervisor - the person employed by the institution of higher education to supervise candidates engaged in student teaching.

Cooperating teacher-the person employed by a school district who is simultaneously directly engaged in teaching pupils in a school and immediately responsible for a student engaged in student teaching; for this study, all cooperating teachers were from core content areas at the high school level.

Core content area-one of the following content areas-English, math, science. Instructional qualities - traits and behaviors related to effective teaching practices, such as questioning, lesson design, and assessment. 
Professional qualities - traits and behaviors related to individuals' beliefs, daily habits, and cooperation with others.

Pupil-youth ages pre-K through 12 who are served by cooperating teachers and student teachers; used to designate between the adult student who is the student teacher and the youth who is the pupil.

Student teacher - that person who has been assigned to complete responsibilities at a particular school over a period of time.

\section{Conceptual Framework}

Evaluating the work of a teacher is complex in that there are elements that are directly observable and others that are implied through what does or does not result in what is observed. Recognizing this complexity, Charlotte Danielson (2007) has developed a framework for teaching. The original intention of the framework was to contribute to the accountability movement propelled by the Interstate New Teacher Assessment and Support Consortium (INTASC), the National Association of State Directors of Teacher Education and Certification (NASDTEC), and the National Council for Accreditation of Teacher Education (NCATE) by fostering conversations about the multifaceted work of teaching (Danielson, 2007).

Danielson's framework is divided into four domains, each then being subdivided into components and, at a more detailed level, elements within those components. Within the framework, there are 22 components in all:

1. Planning and Preparation

A. Demonstrating Knowledge of Content and Pedagogy

B. Demonstrating Knowledge of Students

C. Setting Instructional Outcomes

D. Demonstrating Knowledge of Resources 
E. Designing Coherent Instruction

F. Designing Student Assessments

2. The Classroom Environment

A. Creating an Environment of Respect and Rapport

B. Establishing a Culture for Learning

C. Managing Classroom Procedures

D. Managing Student Behavior

E. Organizing Physical Space

3. Instruction

A. Communicating with Students

B. Using Questioning and Discussion Techniques

C. Engaging Students in Learning

D. Using Assessment in Instruction

E. Demonstrating Flexibility and Responsiveness

4. Professional Responsibilities
A. Reflecting on Teaching
B. Maintaining Accurate Records
C. Communicating with Families
D. Participating in a Professional Community
E. Growing and Developing Professionally
F. Showing Professionalism

Domains 2 and 3 are more readily observable in that they include components that are direct steps within the lesson and physical arrangements of the lesson space.

Domains 1 and 4 are more difficult to observe because they include components that have an impact on the lesson but may not be overtly witnessed.

The qualities identified in Danielson's framework reflect accepted practice for effective teaching, as the State of Illinois Performance Evaluation Advisory Council has identified the core of the Danielson framework as a recommended model for district compliance with the expectations of the new evaluation system, which links an individual teacher's performance with pupil growth. These practices have been identified as relevant in improving pupil achievement, and they are the cornerstone of the required teacher evaluation training modules in the Illinois Growth Through Learning 
Performance Evaluation for teachers and administrators. These modules are based on Charlotte Danielson's (2007) Framework for Effective Teaching (FfET).

The framework is used as the conceptual framework for this study because of the framework's usability in richly describing and sorting the various traits of effective teaching. This usability is critical in determining the factors participating administrators consider in the selection of cooperating teachers. The FfET, as identified by the Illinois State Board of Education, provides common language for evaluators and teachers to use in describing and documenting practices to ensure student learning. Evaluators using this framework are able to develop conversations about teacher practices, conversations that have previously been one sided and occurring solely in the mind of the classroom teacher.

\section{Research Questions}

The research questions of this study focused on a desire to better understand the selection of cooperating teachers and the traits considered most critical by high school administrators in making these selections. In addition, the impact of perception on the selection process was also examined. This study focused on administrators at the high school level. This level was chosen to reduce the variability that would be introduced by selecting schools at a variety of grade levels.

High schools were chosen as the grade level, rather than elementary or junior high, because high school student teachers have an impact on a large number of students at any given time. With a high school teacher typically seeing more than triple the number of students of his/her elementary counterpart in a district, the effect of the student teacher would be significant. In addition, there are significant gaps in pupil achievement 
at the high school level, gaps that are closing, though slowly, at earlier grade levels.

According to the long-term trend National Assessment of Educational Progress

(NAEP) data, there has been no measurable improvement in the average score for 17-year olds in both reading and mathematics since 1971, though students age 9 and 13 for the same years have shown gains as high as 13 points during this same span of years (National Center for Education Statistics, 2013). These data are especially valid because they reflect an assessment that is maintained for multiple grade levels from one organization, as opposed to other statewide tests in Illinois specifically. With the NAEP data as one example of the disparity between the pupil achievement at different grade levels, additional study is worthwhile at the high school level. The following were the research questions for this study:

1. How do administrators describe the process for selecting cooperating teachers in core content areas at the high school level?

2. What professional qualities do administrators consider most important in the selection of high school core content area cooperating teachers?

3. What instructional qualities do administrators consider most important in the selection of high school core content area cooperating teachers?

4. In what ways, if any, do administrators' perception of a staff member within the department, building, or district influences the selection of that individual as a cooperating teacher?

5. What evidence do high school administrators use in selecting and reviewing the effectiveness of cooperating teachers? How does this evidence align with the Danielson (2007) Framework for Effective Teaching?

\section{Study Design}

This study was expected to reveal specific perceptions about the factors considered relevant to the individual participants in the selection of cooperating teachers. 
There were five primary research questions for this study, with all of them contributing to a broad focus seeking to identify how the research of this study could be used to inform professional practice, specifically the cooperating teacher selection process. Research question one focused on the process leading to the selection of cooperating teachers. Research questions two and three focused on the qualities of a cooperating teacher. Research questions two, three, and four focused on the qualities of a cooperating teacher, specifically factors which are not directly stated as part of the placement process but may be revealed in how the experience of having a student teacher is characterized or in how effective teaching is characterized. Research question five focused on the qualities of a cooperating teacher, specifically directly stated or implied factors that reveal how the effectiveness of cooperating teachers is determined, and how these qualities aligned with Danielson's (2007) Framework for Effective Teaching. In order to answer these questions, a qualitative design was applied for the purpose of data collection and analysis.

\section{Sample Selection}

Participants in the study were selected initially based on their district's involvement with the Consortium for Educational Change. According to this organization's mission statement, it is a "nonprofit organization that collaborates with teachers, school and district administrators, school board members and union leaders to improve student learning and achievement” (http://cecillinois.org/about/mission-vision/). By choosing membership in this voluntary organization, districts have indicated an interest in improving teaching and learning through a collaborative effort. Such an interest suggested these districts would have a heightened awareness of the importance of 
improving teaching through all possible avenues, including improving the training of preservice teachers through the intention collaboration of teachers and administrators.

To further narrow the pool for this study, purposive sampling was used, identifying unit districts considered by the Illinois Interactive Report Card to be labeled as large suburban districts of Chicago. Large school districts were chosen for a variety of reasons. Large districts typically incorporate more student teachers in a given year, allowing for patterns of belief and practice to develop. Additionally, large districts include large schools in which multiple administrators are likely to play a role in the placement of student teachers. The increased participation of different administrators increases the opportunity for data on perceptions to be gathered specific to one school. These data were analyzed to identify themes of factors rather than simply summarized as a representation of an isolated individual administrator's perspective. Once these schools were identified, eight in total, random sampling was used to identify the final three districts. For identified districts that had more than one high school, convenience sampling was used to select the participating building.

\section{Data Sources and Data Collection}

Data were ultimately collected from high schools in a total of three districts, with interviews being conducted with two administrators at two of these three districts, and one administrator from the third district. In schools where two administrators were interviewed, one administrator was a building level administrator (principal or assistant principal responsible for student teaching at that building) the other was a department chair of a core area. 
Data were collected through face-to-face semi-structured interviews using researcher-developed interview probes. In addition to the interview probes, there were also two activity components to each interview. Both of these activities served a distinct purpose, as noted in Table 1.

Table 1

Interview Activities

\begin{tabular}{|c|c|c|}
\hline Activity & Description & Purpose \\
\hline $\begin{array}{l}\text { Choose a } \\
\text { Cooperating Teacher } \\
\text { (CT) (Appendix D) }\end{array}$ & $\begin{array}{l}\text { Review descriptions } \\
\text { of potential } \\
\text { cooperating teachers, } \\
\text { identifying why each } \\
\text { would or would not } \\
\text { be likely to be } \\
\text { effective as a } \\
\text { cooperating teacher }\end{array}$ & $\begin{array}{l}\text { Reviewing descriptions of sample } \\
\text { individuals allows study participants to } \\
\text { comment on both positive and negative } \\
\text { qualities without speaking directly about } \\
\text { staff within their school. Discussing the } \\
\text { qualities from these descriptions that were } \\
\text { weighted most heavily also indicates, } \\
\text { implicitly, which qualities are perceived to } \\
\text { be most important in selecting cooperating } \\
\text { teachers. }\end{array}$ \\
\hline $\begin{array}{l}\text { Trait Sort } \\
\text { (Appendix E) }\end{array}$ & $\begin{array}{l}\text { Review qualities of } \\
\text { effective teaching } \\
\text { from Danielson's } \\
\text { framework, ranking } \\
\text { the } 3 \text { most and } 3 \\
\text { least important from } \\
\text { those qualities } \\
\text { provided }\end{array}$ & $\begin{array}{l}\text { Reviewing and ranking these qualities } \\
\text { provides opportunity for study participants } \\
\text { to discuss qualities they may have } \\
\text { struggled to fully articulate. Having the } \\
\text { language provided allows for study } \\
\text { participants to focus their discussion on } \\
\text { the perceived importance of each quality } \\
\text { rather than the identification of such. }\end{array}$ \\
\hline
\end{tabular}

\section{Data Analysis}

Merriam (2009) clarifies that qualitative data analysis is best accomplished when it is completed alongside data collection. The process of analysis is ongoing. Transcriptions of the semi-structured interviews were coded by continually reading the transcriptions and "looking for recurring regularities in the data" (Merriam, 2009, p. 177). 
Transcriptions, field notes, and participant profiles will be brought together, with key ideas being identified. The process used for first round coding was open coding, with all information that seemed noteworthy being commented on in the margins of the transcripts. The second cycle coding was values coding (Saldana, 2013), seeking to identify participants' values, beliefs, and attitudes regarding the selection of cooperating teachers. From these two cycles, themes addressing each of the research questions were identified and documented with support from the interview respondents.

\section{Assumptions}

The following assumptions were made in this study:

1. All study participants would respond honestly throughout the interview process.

2. The intention of each of the participants involved in the study would be to provide unbiased information about the overall student teaching experience and placement processes.

3. Based on job title, participants had previously participated in a student teacher placement in some capacity as part of his/her position. This assumption, being central to the study's reliability, was confirmed during the interview process.

4. Responses to interview questions could be accurately coded, with reliable themes being identified.

\section{Delimitations}

The factors perceived as critical for cooperating teachers through the lens used here, that of C. Danielson's (2007) Framework for Effective Teaching, though perceived by individuals in given districts, may in fact represent - at least in part - the perceptions 
of administrators in other districts. The factors perceived as critical may also be viewed through other conceptual frameworks or theoretical lenses, though this study was limited to high school administrators, specifically those in large suburban school districts.

\section{Limitations to the Study}

The study was limited in that the data represented only a narrow group of schools. While practices at other schools may be similar to practices of schools in the study, the extent of this similarity is unknown. Therefore, the results of the study may not be generalized to all school settings. Additionally, the study specifically reflected on the qualities considered important when administrators choose cooperating teachers, with no attention given to the perceptions of the student teachers.

\section{Organization of the Study}

Chapter I provided an overview of the problem and its context within the field of education. It included a brief description of the conceptual framework, as well as a list of key definitions and terms. The focus of Chapter II is a discussion of the important role of teachers in pupil achievement and an argument for the function of Danielson's framework in evaluating teachers. The signature pedagogy for teaching, with specific attention to the student teaching component, is also discussed. The methodology and study design elements are fully explained in Chapter III. Chapter IV will review the study findings and identify themes present in the data. Chapter V will include conclusions from the study and provide recommendations for further related research and analysis. 


\section{CHAPTER II}

\section{REVIEW OF LITERATURE}

\section{Introduction}

In the subsequent review of the literature, three central ideas emerged: (a)

Teachers are the most important factor influencing pupil achievement; (b) The signature pedagogy of teaching, most specifically the quality of student teaching placements, has significant impact on the future success of a teacher; and (c) Cooperating teachers have the most significant impact on the growth of a student teacher in the teacher preparation program. The interconnection of these various concepts is that the cooperating teacher influences the student teacher who, in turn, influences pupil achievement. The links here reflect that the cooperating teacher is a major factor in determining the success of the student teacher's future pupils.

The cooperating teacher's role is one of the three partnered roles within the student teaching triad. The cooperating teacher works closely with the student teacher, providing guidance and feedback on a day-to-day basis. The university supervisor, the other role in the triad, provides support from a distance and focuses on ensuring the program requirements are met during the student teaching experience.

Within these connected factors, the cooperating teacher's role will be explored specifically, including a summary of the (a) benefits of hosting student teachers, (b) gaps between student teaching experience and effective teaching, and (c) narrow view of the 
responsibilities of others within the student teaching cooperative. The benefits of hosting student teachers within a district appear to be beneficial for both teachers and students but not necessarily for pupils. In addition to the perceived benefits, a second idea emerges: two distinct gaps between the student teaching experience and effective teaching. The first gap is the disconnection between the university expectations and the hosting district's expectations, which leads to confusion for the student teacher. The second gap is the disconnection between the student teaching requirements and standards for effective teaching. The second gap leads to a disservice for the pupils. The third idea that emerges in examination of literature related to the cooperating teacher's role is the narrow view of the responsibilities of others within the student teaching cooperative.

Student teachers are expected to develop competency in all of the Illinois Professional Teaching Standards: Content Knowledge, Human Development and Learning, Diversity, Planning for Instruction, Learning Environment, Instructional Delivery, Communication, Assessment, Collaborative Relationships, Reflection and Professional Growth, and Professional Conduct (http://www.isbe.net/profprep/PDFs/ ipts.pdf). The challenge is identifying the best ways for student teachers to develop these skills and how others, such as the cooperating teacher, contribute to the development of these skills.

\section{Importance of Teacher in Pupil Achievement}

\section{Normal School Teachers vs. Highly Qualified Teachers}

Horace Mann created the first normal schools for teachers in Massachusetts in the late 1800 s. These schools quickly prospered throughout the U.S. They focused on providing basic training for individuals who would serve as teachers for a variety of 
communities (Shulman 1986). The skills required for the 1875 teacher were primarily content skills, with the exception of the expectations for "Theory and Practice of Teaching." By contrast, Shulman's comparison to the focus of skills from the 1980s shows an almost complete shift to pedagogy over content. Practices in teacher training have led to the predominance of teacher-centered and content-centered rather than student-centered and learning-centered classrooms (Darling-Hammond, 2006). These practices began long ago, and, despite research that should point education in a different direction, teachers are slow to change their instructional practices (Marzano, Pickering, \& Pollock, 2001).

This transition from 1875 to the modern times shows a significant positive and a significant negative. While the awareness of the knowledge of best teaching practices and student learning theory is a significant improvement in pedagogical focus, the apparent replacement of content knowledge is not. A basic level of knowledge of teaching is seen as more important than knowledge of content or-more importantly in moving toward the $21^{\text {st }}$ century - the ability to marry content and pedagogy. In addition to the gap evidenced in Shulman's (1986) examples, another gap in level of knowledge is shown in the state of Illinois with the requirements for the Test of Academic Proficiency (TAP) being replaced, at the choice of individual pre-service teachers, by an ACT score. While the logic of this is appropriate, the actual score required to replace with an ACT composite score is a 22. As a point of comparison, the middle $50 \%$ of students offered admission to Illinois State University's entering class had an ACT composite score of 2226, and Eastern Illinois University had an average ACT composite of 21 in 2012. While it is acceptable to use ACT as a replacement for a TAP score, the composite ACT is not 
holding teachers to a very high academic standard, since the average ACT composite score in Illinois is only 21 . The picture as a whole shows that the expectations of strong content knowledge are low for those entering the teaching profession.

To attend to concerns regarding quality, NCLB included requirements for Highly Qualified (HQ) status for teachers and requirements for which teaching roles required a HQ teacher. Generally, individuals are required to complete a certified teacher preparation program or fulfill alternative qualifications such as a certain amount of university coursework in a content area. The trouble with the HQ guidelines is that great variance exists in the university programs, essentially resulting in HQ having little meaning. While the federal Highly Qualified mandate has had some impact on certain aspects of teacher quality, it has done little to improve the quality of the teaching pool overall.

According to the U.S. Department of Education's National Center for Education Statistics report entitled The Condition of Education 2012, a larger percentage of fulltime teachers held a post baccalaureate degree (master's degree, education specialist or professional diploma, first professional degree, or doctoral degree) in 2007-08 than in 2003-04. This increase includes those individuals who may have turned to the education profession as a second career. While the percentage of those with an advanced degree increased by $4 \%$ during this time, the average years of experience (14 years) remained the same. More concerning is that the percentage of individuals who had 20 or more years of experience decreased during this time by about $3 \%$. This decrease in experience occurs amidst the decision making of a teacher in choosing instructional practices. This critical decision making within diminishing ranks of experience occurs as teachers today 
are serving students who are increasingly culturally and linguistically diverse (Goodwin, Lefkowits, Woempner, \& Hubbell, 2011).

\section{Measuring Effectiveness: Design of Danielson's Framework}

Honoring the complexity of teaching and teacher evaluation, Danielson (2007) developed a Framework for Effective Teaching (FfET). The original intention of the framework was to contribute to the accountability movement propelled by the Interstate New Teacher Assessment and Support Consortium (INTASC), the National Association of State Directors of Teacher Education and Certification (NASDTEC), and the National Council for Accreditation of Teacher Education (NCATE). The FfET was designed to foster conversations about the multifaceted work of teaching (Danielson, 2007).

Danielson's first book on the FfET was published by ASCD in 1996, at the beginning of the standards movement. In the foreword of this text, the then president of ASCD, Frances Faircloth Jones, described the FfET as a "road map" (Danielson, 1996, p. vii). It is important to note the framework is not a list of step-by-step directions, but rather a view of how to journey from teaching today to the teaching needed to prepare thinkers in the $21^{\text {st }}$ century. The FfET is divided into four domains, each of them subdivided into components and, at a more detailed level, elements within those components. There are 22 components in all. Domains 2 and 3 are more readily observable in that they include components that are direct steps within the lesson and physical arrangements of the lesson space. Domains 1 and 4 are more difficult to assess because they include components that have an impact on the lesson but may not be overtly witnessed.

It is helpful to examine a particular component within each of these "behind the scenes" domains. Component 1B focuses on a teacher's knowledge of his pupils, 
including the knowledge of child and adolescent development. If a teacher does not have a full understanding of the social characteristics of his sixth grade pupils and how those social characteristics will be exhibited, a successful lesson is unlikely. In talking with the teacher during a pre-observation conference, a colleague or evaluator may not specifically ask the teacher what types of social interaction are typical of sixth graders, but such knowledge, or lack thereof, will be readily apparent when pupils are grouped without noting gender or accommodating for the varying levels of maturity among sixth graders.

Elements within the Domain 4 components can be equally impactful, though the specific components are not likely to be referenced in the lesson. For example, communicating with families, Component $4 \mathrm{C}$, regularly and productively can completely redirect the behavior of a child who might typically struggle to concentrate. While a particular child may be disobedient and off task in other areas of the school, a teacher who is communicating with that child's family may be able to foster a different relationship. As a result, the teacher may be able to design a lesson that includes activities where that pupil is engaged and learning, actively participating as a result of the triangular relationship that has been built between the pupil, parent, and teacher. Though Domains 1 and 4 components are more difficult to observe during any given lesson, they are no less important than the components included in Domains 2 and 3.

Significant in the structure of the FfET are the levels of performance and how they function. Rather than having a top level that teachers expect to reach and maintain, the distinguished level serves as a mountaintop experience, described by some as "a good place to visit, but don't expect to live there" (Danielson, 2007, p. 41). The intention is for 
all teachers to strive to meet the distinguished level in four of the domains, but Danielson herself recognizes the opportunity for that accomplishment depends on more than the teacher. While the teacher is in control of the safety of the classroom, the pupils must be in control of their learning.

Also significant in the structure of the FfET is its lack of adherence to any one particular teaching methodology. While some methodologies, such as modeling or Socratic seminar, may be more closely aligned with certain elements in the domains, there is no specific methodology the FfET requires to be used at all times. While explicit lecture may not allow for a distinguished rating in component 3C (engaging students in learning) under the component of grouping of pupils, the lecture may be most appropriate for pupil learning based on the instructional goals of the lesson. This open connection framing is consistent with the need for flexibility in response to pupil learning in a given lesson or unit. Danielson (2007) cautions that such flexibility is always to be determined by what pupils need and not as a result of other factors that may be labeled as teacher style.

The FfET was born out of Danielson's work on beginning teacher licensure measurement with the Educational Testing Service in the late 1980s. During this time, Danielson was collaborating on the development of the PRAXIS Series, specifically PRAXIS III: Classroom Performance Assessments. The research that drove the development of the initial criteria included in the FfET is based on the Development of the Knowledge Base for the PRAXIS III: Classroom Performance Assessments Assessment Criteria from Dwyer (Dwyer, 1991, 1993; Dwyer \& Villegas, 1993), which was informed a great deal by actual teacher practice. In addition to reviewing practice 
with active classroom teachers, standards from organizations, such as the Interstate New teacher Assessment and Support Consortium and the NBPTS were also studied.

Though early on Danielson (1996) was focused on her specific assignment to train assessors who would use the newly developed PRAXIS III, Danielson saw the significant benefits this type of reflection had on the evaluators themselves. This led to her identification of a need for expanding the criteria into a framework that could be used for comprehensive evaluation of pre-service, beginning, and veteran teachers alike.

Evaluation can be a powerful tool in raising teacher quality and, in turn, improving education. Teacher evaluation using this framework has two basic purposes: ensuring the quality of instruction provided to pupils and promoting professional learning opportunities for teachers (Danielson, 2008). If used appropriately, the feedback provided to teachers can guide them in building their professional practice at the classroom level. That feedback, as a type of classroom-embedded professional development, is absent for most teachers beyond the phase of student teaching.

Consistent with these basic overarching purposes is Haefele's (1993) posit that teacher evaluation can be simultaneously used for formative and summative purposes. Realistically, Haefele acknowledges that a strong teacher evaluation system is necessary should there ever be legal action against a school district based on the conclusions drawn from the tool. As a corollary, a strong tool can also be used as a means of calling attention to and potentially rewarding positive behavior. The tool can be used to inform practice in process and to reflect on past practice.

Danielson's FfET is a powerful tool because it brings together practice, research, and theory. The tool delineates and attempts to quantify, as much as possible, the 
elements of effective teaching. The basis of the framework is in the mind of psychometricians like Dwyer, in the studies of researchers like Shulman and DarlingHammond, and in the hearts of teachers everywhere. The framework views teaching as a multi-dimensional and constantly changing process. The FfET is deeply rooted in Piaget's (1976) constructivist approach to teaching and learning. This approach relies on high pupil engagement (Fosnot, 1989).

Brooks and Brooks (1999) identify guiding principles of constructivism related to problem-based learning, primary concepts or essential questions, pupil perspective, flexibility and responsiveness to pupil learning trajectories, and assessment during learning rather than as a separate act. The principles revolve around active engagement of the pupil as a contributing member of the lessons. With pupils fully participating, rather than just being present, they are engaging with the material and preparing for longterm application and transfer of skills and knowledge (Brooks, 1990) as necessary in the $21^{\text {st }}$ century. These practices are the core of the FfET, which includes multiple references to pupil responsiveness, pupil ownership, and pupil inquiry (Danielson, 2007).

Pupils were at the center of Dewey's vision of education, too. In "My Pedagogic Creed," Dewey (1897) argued for the instruction of science and history only so much as these subjects were related to the lives of pupils. This point aligns directly with the FfET Domain 1B component which calls for teaching to respond to pupils' developmental, social, and learning profiles (Danielson, 2007). The FfET is a tool leaders can use to operationalize the best tenets of Dewey's philosophy.

Danielson highlights the FfET is not a stand-alone tool. Appropriate professional support is necessary for the framework to support pupil learning. This support may come 
in the form of administrative meetings and classroom visits, mentoring, instructional coaching, or independent work with additional activity sheets to help teachers reflect on their own practice (Danielson, 2009). The framework focuses on the inputs rather than the outcomes of the lesson. The specific language frequently refers to teacher behavior, but these various teacher behaviors should be supported by artifacts demonstrating pupil learning.

For example, Component 1B requires teachers to demonstrate knowledge of pupils. Within the elements at the distinguished level, a teacher is expected to "display understanding of individual students' skills, knowledge, and language proficiency" (Danielson, 2007, p. 50). While this is a behavior of the teacher, the teacher may evidence this element by providing sample assignments that are differentiated based on pupil readiness. This example reinforces that while some of the specific behaviors of the FfET are teacher behaviors, these behaviors are strongly connected to pupil learning.

Some might argue performance-based evaluation tools like the FfET are a measure of student learning, but such evidence is not strong. While the instructional practices represented on Danielson's (2007) framework are those shown in research to be positively correlated to increases in student achievement, there are other mediating factors that could interfere with this solid transfer occurring. The evaluator, as one issue, may use the FfET improperly. Whether because of a desire to be overly supportive or just being unprepared to appropriately monitor behaviors, such an evaluator could observe a classroom atmosphere where the teacher could be rated as proficient or distinguished in all of the domains when little learning is occurring. In addition, classroom practices could be such that appropriate instructional practices are in place, but 
that would not necessarily correlate with a high level of pupil achievement. The pupils may be learning but had begun with skill sets significantly lower than those required on the assessment, so their learning would not meet the benchmarks of the measurement.

Past efforts to improve teacher effectiveness through evaluation have failed for a variety of reasons. In a report sponsored by the Gates Foundation, Donaldson (2009) notes that instrument failure, culture constraints, and limited time manipulated the effect of evaluation reform in some places in the past. Culture constraints are some of the most tentacled challenges to evaluation as a means for education reform (Donaldson, 2009). Constraints can occur from the culture within an individual school or district or on a more grand scale. For example, the effect on school climate that could be felt following a negative evaluation of a popular tenured staff member might be weighed carefully by a novice administrator. In turn, the culture of the evaluation as a valued tool begins to erode, leading to potential constraints from teachers associations.

Culture constraints may also be felt as evaluators seek to differentiate for various roles in the organization. Differentiating for media specialists or school counselors may be seen as favoritism by some, while failure to do so could result in resistance from others.

Difficulties with effective implementation of a tool and the debate over valueadded teacher evaluations occurs with evaluation tools today; the FfET is no exception. However, the FfET is flexible enough to work with or without value-added measures (Danielson, 2000). Value-added measures can show the fundamental role teachers play in the education of pupils; however, challenges with such measures include using test scores as the sole indicator of a pupil's growth, limited availability of data for teachers in 
certain content areas, and the inextricable nature of measuring growth for a pupil with multiple teachers (Hightower, Delgado, Lloyd, Wittenstein, Sellers, \& Swanson, 2011). If regulated and adjusted to account for these issues, a value-added component measured on standardized normative or local assessments could be used as partner evidence with the domain ratings in the FfET. The framework could also function without such additional information for teachers whose subject areas are not monitored directly on these assessments. The effectiveness of value-added measures as part of this type of evaluation tool is determined by the evaluator, the targets, and the quality of the assessment measuring the value. Teacher evaluation is critical because teachers are in a unique place of potential influence beyond that of other stakeholders in education. The role of teachers is significant, so the training of teachers is critical.

\section{Impact of Signature Pedagogy of Teacher Development}

\section{Value of Signature Pedagogy}

Examining the signature pedagogy for different professional fields provides background on the habits of mind, hand, and heart (Shulman, 2005) required in that profession. The exploration of such matters in other fields, such as medicine, was common, and Shulman brought this same level of analysis to the field of teaching in his early research, as articulated in "The Psychology of School Subjects" (Shulman, 1974). In this essay, he argues for the need to "understand how practitioners really do their work - not only what they do, but how they deliberate, judge, make decisions, and assess consequences" (p. 120). These habits represent what individuals in a field are trained to think, do, and believe, whether through enculturation or intentional coursework and training. 
A profession's signature pedagogy evidences insight into intellectual, technical, and moral details that may be unspoken but are considered critical for continued practice in that profession. Signature pedagogies, by definition, are pervasive and routine; they represent the teaching that is unique to that individual profession. A signature pedagogy may include the initial pedagogy that establishes the outline of the professional preparation, the capstone experience, and a portfolio of sorts (Shulman, 2005).

Three major structures are at play in signature pedagogy. Surface structure is comprised of the "concrete, operational acts of teaching and learning, of showing and demonstrating, of questioning and answering, of interacting and withholding, of approaching and withdrawing." Deep structure includes the "set of assumptions about how best to impart a certain body of knowledge and know-how." Implicit structure is the "moral dimension that comprises a set of beliefs about professional attitudes, values, and dispositions" (Shulman, 2005, pp. 54-55). The implicit structures may be even more powerful than the surface structures, as the individuals in the profession may not even be aware of some of the beliefs that transcend their professional realm. By studying the specific components of what is ingrained into particular professions, patterns of beliefs and cultural standards can be identified. It is through the review of these patterns that gaps and overlaps can be exposed, and plans can be developed for reform.

\section{Signature Pedagogy for Teaching}

A comprehensive signature pedagogy for teaching is a work in process. While this is an unsettling statement for those exploring this concept theoretically, this process status is even more knotty for practitioners and teacher educators. Currently the signature pedagogy for teaching, based on aggregate research, suggests that teachers learn how to 
teach (a) based on their own experiences as students, (b) through varied levels and demands in coursework and interaction with content, and (c) following some version of a student teaching experience. The student teaching experience, by title, is constant. The expectations and learning prior to and therein are not.

Specifically in the field of education, Shulman contends a teacher needs to be viewed more clinically as an "agent" $(1974$, p. 120) than is typically the case in the signature pedagogy for teaching. Teachers are more than simple tools who deliver instructional interventions; rather, they are the agents who are determining the need for, the level of, and the process of receiving the intervention. Different types of knowledge are initially identified by Shulman (1986): content knowledge, pedagogical content knowledge, and curricular knowledge. Shulman extols the importance of effective teacher training including the appropriate balance of these areas of knowledge in their multiple forms, as well as the inclusion of the other instructional knowledge necessary for individual grade levels (classroom management, lesson design, etc.) (Shulman, 1987).

Areas and forms of knowledge. Referring back to the comparison of teacher expectations from the 1870 s to the 1980 s, the type of knowledge is not really a one or the other need; instead, as shown by Shulman in identifying the signature pedagogy for teaching, there is a need for a combination of knowledge in multiple areas. Within these three areas, there is also what he characterizes as forms of knowledge for teachers: propositional, case, and strategic knowledge (1986).

Propositional, case, and strategic knowledge serve important but underused and misunderstood functions in the signature pedagogy for teaching. Propositional knowledge refers to the general principles and norms within teaching. An example of 
prepositional knowledge would be the practice of having pupils read aloud and then asking them a question. This is knowledge that many teachers logically think is sound, as they do not realize the pupil least prepared to answer a question following a reading is the pupil whose brain focus has just been directed to decoding, while she was reading aloud, rather than comprehending, as the other pupils who were listening.

Case knowledge refers to the examples that are used so commonly that they become a type of parable or prototype. An example would be teachers who repeatedly use a certain grouping of pupils, as the lore of the school has passed on that the principal always likes to see pupils grouped in this way and responds favorably on the evaluations of teachers who use this grouping.

The amount of time a teacher has with pupils in any given class is an example of strategic knowledge. Teaching time is different than time for a lawyer who can bill more hours or time for a doctor who can schedule an additional procedure or write another prescription. The teacher always faces the same limited number of school days and, for secondary teachers, a finite number of minutes for each day. Teacher training, as discussed by Shulman (1987) in "Wisdom of Practice," allows for varying success in using this time effectively. Given the challenges of effective questioning and proper use of wait time, teachers struggle to use time, whether in large or small quantities, to their fullest potential.

Upon careful review, the relationship between Shulman's areas of knowledge and the types of knowledge indicates a need for intentional and continuous balancing of knowledge of material (content) and knowledge of people (pupils), as represented in the Figure 1. 


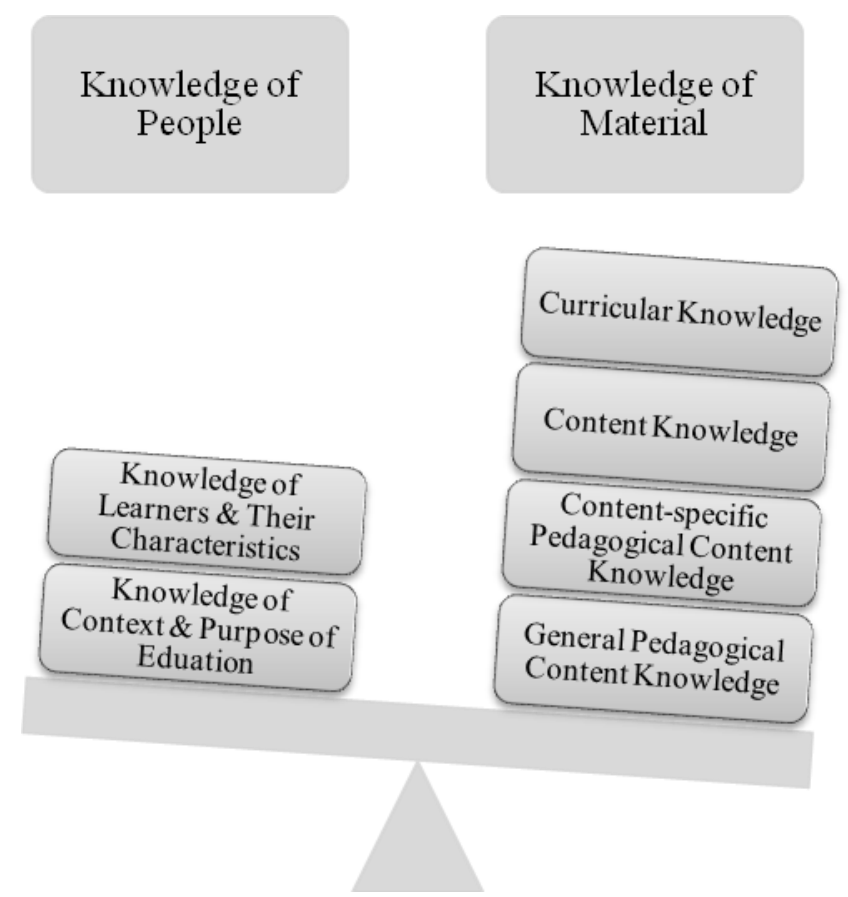

Figure 1. Balance of Knowledge in Signature Pedagogy for Teaching

Ignoring one form of knowledge at the expense of another, as was the case in the early normal schools, leaves teachers unprepared for the work ahead of them. In addition to what signature pedagogy specifies, there is also evidence about a profession in what is not imparted within such pedagogy. Within the signature pedagogy for teaching at this time, there is no mention of the value of continuing to add to the knowledge within the three areas. Instead, as mentioned in the compilation work Teaching as the Learning Profession, "teaching is fundamentally a self-evident practice" (Kennedy, 1999, p. 54). This is to say that the effectiveness of teaching is seen as evidence of itself, which is circular logic. With teaching evaluating itself, there is little opportunity for an outside perspective to add to the profession with any meaningful reform. There was also no mention of the larger context of teaching, related to policy, in Shulman's initial 
researching on the signature pedagogy for teaching.

Contexts for teacher training. The signature pedagogy for teaching reflects knowledge is gained through the "received wisdom model" (Kennedy, 1999, p. 54). In this model, information and skills are not only explicitly taught; they are also gathered through one's own experiences. Specifically in teaching, the majority of the information learned about teaching, argues Kennedy, is gathered through one's own varied experiences as a student. The information gained through these individual experiences is not inherently problematic; however, the quality of the experiences and the limited opportunity and capacity to reflectively review these experiences can be an issue. Without intentional reprogramming of these experiences, through a strong teacher education program, individuals are not able to overcome this knowledge base. Lortie (1975) explained that much of what teachers learn is based on what they experienced from their own teachers, with the length of that observation being far longer and more concentrated than any student teaching or pre-service clinical experience.

An effective program of teacher instruction will provide sample cases and the experience of knowing when and how to apply these prototypical cases in novel circumstances. Kennedy (1999) explains there are three interconnected contexts of teacher training though not all three are attended to with the same integrity in all teacher preparation programs (Darling-Hammond \& Hammerness, 2005). 


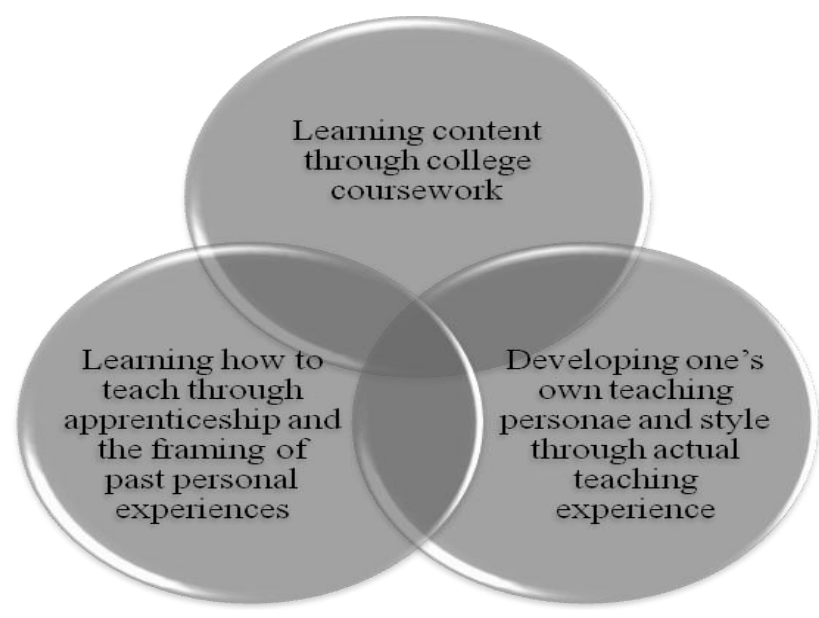

Figure 2. Kennedy's Contexts of Teacher Training (1999)

The critical component is the reframing that should happen during pre-service experiences. "Professional education ... is preparation for accomplished and responsible practice in the service of others" (Shulman, 2005, p. 53). The reframing helps teachers to reflect, based on learned skills and content, on how their own personal experiences do and do not match their own developing practice. While the interconnections of these contexts explain where teachers learn, it is extremely difficult to determine where the effect of each of these contexts begins and ends (Wilson, Floden, \& Ferrini-Mundy, 2002). Determining the impact of one's experience over coursework, or the opposite, has proven difficult (Hammerness, Darling-Hammond, \& Bransford, 2005).

\section{Culture of Isolation}

Beyond the initial framing of signature pedagogy for teaching, Shulman (1997) has continued research, with support of the Carnegie Foundation, to develop a more comprehensive view. His later work adds an emphasis on fostering a community of learners, which has exposed an additional component of context to signature pedagogy. 
In "How and What Teachers Learn: A Shifting Perspective," Shulman \& Shulman (2008/2009) further expand the previous thinking about the contexts of knowledge to include the various factors that are constantly impinging on and being effected by a teacher's knowledge. These factors are elements of the learning community that exist at both the individual and community levels.

A teacher's reflection is effected by his motivation, daily practice, knowledge, and vision for pupil learning as a whole. Surrounding these influential factors are the community factors regarding incentives, expectations, shared knowledge, and vision (Shulman \& Shulman, 2008/2009). The final context of all of this learning is the policy factors. Policy envelops all of the learning, and learning can never exceed policy (Maxwell, 1998). Policy can either function as a stifling lid on the steam of learning, or policy can function in a new way. As a hot air balloon, policy can be buoyed by the learning, the air, within it. Learning, if viewed differently in the signature pedagogy for teaching, actually can inform policy.

\section{Teacher Preparation Connects to Pupil Learning}

Connecting theory to practice is critical but complex (Brouwer \& Korthagen, 2005). With teachers playing the pivotal role in pupil achievement, better understanding how this impact works is important. Knowing how teachers make a difference is even more important than knowing that teachers make a difference in pupil learning (Diez, 2010). Meta-analysis (Wineburg, 2006; Boyd, Grossman, Lankford, Loeb, \& Wyckoff, 2009) has described universities and colleges as inconsistent in how they are measuring the power of teacher preparation programs. Having different measurement tools leads to conflicting conclusions drawn from the data gathered through these tools. Some 
universities are measuring growth without accounting for pupils' socioeconomic factors, while — at the opposite end of the spectrum — others over-analyze the role these factors may play.

Regardless of what universities are currently doing, Darling-Hammond, alongside the statewide standards movement transforming education, has advocated for careful assessment of program components (2006), identifying what is most effective with the strongest programs (2010). Darling-Hammond has gone so far as to call for the development of specific policies to establish and maintain effective teacher preparation programs (2006).

\section{Teacher Preparation Connects to Future Teaching Success}

Student teaching has not always taken place within myriad school environments as it does today, yet the basic template of the student teaching model remains the same as it was described by Del Popolo in an administrator advice article in 1960. Prior to World War II, student teaching was limited to laboratory schools and experimental groupings on university campuses (Koerner, 1992), reinforcing the importance of this phase as continued training for the future educator. Today, professional development schools, as they are now called, are much more limited, and the majority of student teachers are placed in traditional school environments. Whatever the location, student teaching prepares individuals for the demands and interactions that are part of a teacher's daily professional life.

Research on the valuable components of an effective student teaching experience has been conducted, with the focus being on where the student teaching takes place. One model that has been advocated in the past and the present focuses on student teaching 
taking place in a professional development school that is designed for pre-service teachers to hone their skills in an environment closely connected to their university experience (McKeag, Koll, \& Herzog, 1978), characterized as a "hybrid" area (Martin, Snow, \& Torrez, 2011). Within this model, however, there still can be ambiguity regarding the cooperating teacher's role (Graham, 2006).

Another model described by Cornbleth and Ellsworth (1994) recommended establishing clinical faculty roles wherein full time teachers could serve as university staff who receive specific training as part of their role in the student teaching triad.

The value of both of these models is that they build on the best practices about learning that focus on the value of hands-on experiences (Conklin 2009). However, the gap with both of these models is the distinct separation between the student teaching environment and the typical school where a new teacher will begin his or her career (Moore, 2003). Without the opportunity to face real-world problems and to be socialized into the faculty of a school, beginning teachers may not be fully prepared for their new positions.

Mary Hatwood Frutell stresses the critical role pre-service training plays in preparing effective teachers for the $21^{\text {st }}$ century (National Commission on Teaching and America's Future, 2008). She suggests a required 2-year induction program for all new teachers, which is well beyond the current requirements in Illinois. What is unclear from Frutell's argument, however, is exactly what she believes should be included in such an induction program.

As has been shown in research on the varying effectiveness levels within different student teaching triads, the quality of training provided for teachers depends on the 
individuals involved in the training as much as it depends on the structure of the training itself (Diez, 2010). Without a clear description of how the induction program should be structured and who should be involved, Frutell's vision may not be any more successful than the system that prepared teachers for the $20^{\text {th }}$ century shopping mall high school (Powell, Farrar, Cohen, 1985). K-12 schools must begin participating in this dialogue with louder voices, with administrators being the guardians of those voices.

\section{Role of Cooperating Teacher in Student Teaching Placement}

Gaps between theory and practice extend throughout education (Shulman, 2008/2009). Bridging these gaps requires that the information of practitioners be shared more publicly and be verifiable in specific contexts. This gap between theory and practice, according to some, exists because of the dichotomy established with the beginning of educational research at the University of Chicago (Hiebert, Gallimore \& Stigler, 2002). Individual experiences will be part of the background of all teachers due to the received wisdom (Kennedy, 1999) of their own schooling experiences. The importance of teacher education is in helping future teachers make sense of these experiences through an intentional training program. The responsibility for a successful student teaching experience falls on multiple partners: college or university supervisor, student teacher, cooperating teacher (classroom teacher), and the building administration. Without cooperation from all of these individuals, the student teaching experience will not be a success for the student teacher or for the pupils being served.

It is during this student teaching experience that the study becomes reality as the focus for the student teacher is transferred from success for teachers to success for pupils (Webber, 1994). Various universities explain this transition in different ways. For 
example, the Illinois State University student teaching statement of purpose describes the skills honed during the student teaching experience:

Student teaching is that part of the teacher education program when a student is responsible for guiding, directing, and evaluating the learning activities of a group of pupils under the guidance and supervision of a professionally certified and competent member of the teaching profession. (http://www.coe.ilstu.edu/ teachercenter/cecp/student_teaching)

The student teaching experience is a frenzy of energy.

Teacher after teacher, including myself, can instantly recall specific details of their own student teaching experience. Whether the memory is perceived as having been more positive or more negative, the overall experience leaves an indelible mark on one's memory. Student teaching is the pinnacle of an education major's university experience, the last step major before moving into the professional teaching world. State requirements see such value in student teaching that without a successful student teaching experience or an acceptable waiver, individuals are not permitted to become certified to teach in the state of Illinois (Ill. Admin. Code ch. 23, §25:620, 2004, p. 227). Student teachers are expected to develop competency in all of the Illinois Professional Teaching Standards: Content Knowledge, Human Development and Learning, Diversity, Planning for Instruction, Learning Environment, Instructional Delivery, Communication, Assessment, Collaborative Relationships, Reflection and Professional Growth, and Professional Conduct (http://www.isbe.net/profprep/PDFs/ipts.pdf). The challenge is identifying the best ways for student teachers to develop these skills and how others, such as the cooperating teacher, contribute to the development of these skills.

Energy and ingenuity are not enough for a student teacher to find success, though. The other components required for achieving success are provided by the cooperating 
classroom teacher, because it is this individual who is responsible to model for and train the student teacher to apply information. The gaps between practitioner knowledge and theory researcher make this modeling and training all the more critical.

While many professions include a pre-employment internship, few other new professionals are expected to achieve the same level of independent work necessary of a first-year teacher. Student teaching is the culminating application of content and pedagogical studies; it serves as the full-time opportunity for future professionals to apply theories and research in a true-life setting with students who respond as individual people. Student teaching has not always taken place within various school environments, however. Prior to World War II, student teaching was limited to laboratory schools and experimental groupings on university campuses (Koerner, 1992). Whatever the location, student teaching prepares individuals for the demands and interactions that are part of a teacher's daily professional life. Preparing future teachers to work with children is a privilege, but, like other privileges, it comes with responsibilities.

The cooperating teacher provides the practical knowledge that cannot be gained from book study and mock lesson delivery. This practical application merges together instructional design with classroom management savvy. The management toolbox of a cooperating teacher is expected to far exceed that of a typical student teacher, and this "thinking on your feet" is the exact skill that can only be learned in a real school setting with real learners. It is this in-the-moment thinking that provides teachers with the experience to be "dilemma managers" when the issues of learning do not match the details of a textbook case study (Lampert, 1985). 


\section{Importance of the Student Teaching Experience}

The teacher has a significant impact on pupil learning, so it is important to understand the factors that contribute to developing teachers who can have the most positive impact on pupils. The cooperating teacher, having daily interaction with a student teacher, determines how the student teacher will ultimately view the power of teaching in changing the lives of pupils. While the teacher has a significant impact, it is important to ensure this impact is positive, a determination that is heavily influenced by the cooperating teacher assigned to an individual student teacher (Hoy \& Woolfolk, 1990). Student teachers, believing in the potential power of their impact on pupils, will work harder to ensure this positive impact becomes reality.

In addition to setting the course for a positive view of pupils, cooperating teachers also influence student teachers in their level of reflection. Reflective practice will allow the student teacher, once a professional, to identify how to have the positive impact on pupils they believe to be possible. In order to do this, it is critical that individuals become reflective about the experiences they had as pupils. Without this intentional reflection and awareness, student teachers often teach as they were taught rather than as they were taught to teach (Bolin, 1988; Collier, 1999). Reflecting on the personal and programmatic factors influencing a student teacher leads the student teacher to be more intentional in his/her own practice.

Diez's research fire has been ignited by a fine distinction: the gap between knowing that teacher preparation programs influence future candidates' teaching and knowing how such an influence occurs. She argues this gap in the research has limited the progress teacher preparation programs need to make in improving the quality of their 
future graduates. Though she places this identified gap within the context of the standards movement, Diez (2010) does not believe the standards, the expectations, are enough if research does not clearly show the distinct path between the preparation of teachers toward reaching these standards and actual improved pupil learning. Specifically, she explains how a focus on helping "all students to learn" (Diez, 2010, p. 441) has forced teacher preparation programs to become more intentional about the connection between teacher quality and data-evidenced student achievement.

Programs that prepare teachers are inadequate for a variety of reasons: some simply because of time; others because of the type of alternative certification they provide. Such inadequacies are not consistent across all programs, but they are common enough to be considered more than isolated organization-specific issues. Additionally, the thick political climate likens education to a helium-filled balloon that appears to be trapping learning within itself. If more helium (more political force) is added, the balloon will burst. Similarly, without some sort of additional air (preferably fresh oxygen) in the form of new clear direction, the balloon (education) will ultimately deflate to near nothingness. Increases in policies over the past 20 years, such as required state standards and the No Child Left Behind Act, place additional pressures on schools and, in turn, on teachers.

Improving the teacher preparation programs starting at their roots requires certification be examined more deliberately, as done by Boyd, Grossman, Lankford, Loeb, and Wyckoff (2009) in New York, to identify and reproduce the most effective program components. Darling-Hammond (2010) highlights the importance of what she coins "expert guidance" during these pre-teaching practice experiences. Such a focus 
supports the important role of the cooperating teacher in the student teacher learning to be effective. Her recommendations go one step further in suggesting universities partner directly with schools to improve the quality of the overall school in which pre-service teachers will be placed. While Darling-Hammond (2010) believes such efforts begin with partnerships between universities and schools, she admonishes governments to require teacher education programs are of high quality, even if that means providing financial support to programs and beginning teachers. This is a huge step beyond cooperating teacher professional development provided through in-services of years past (McKeag, Koll, \& Herzog, 1978).

The role of the cooperating teacher cannot be underestimated, as this individual teaches the student teacher how he or she will function in the greater school environment. Most qualitative research on this topic has focused on the roles of those involved in the student teaching triad: student teacher, cooperating teacher, and university supervisor. Valencia, Martin, Place, and Grossman (2009) criticize most analysis has not investigated the simultaneous roles and perceptions of all three triad members, typically focusing on only one or two. This argument for the limitations of the perception research is similar to the gap in the literature on the role of administrators in the student teaching placement process. With research currently focusing on the perceptions of student teachers regarding their cooperating teachers (Conderman \& Pedersen, 2006), examining the role of building and district administrators is a missing component. Administrators' selection of cooperating teachers begins the process that research has shown will ultimately determine a teacher's success in merging theory and practice. 
Though universities outline the basic responsibilities of the cooperating teacher, the perceptions of cooperating teachers suggest their role is still rather undefined, with some cooperating teachers seeing themselves as an "ambivalent participant" (Koerner, 1992). Over the past 50 years, the need to clarify these responsibilities has been consistent (Campbell \& Williamson, 1983; Grimmett \& Ratzlaff, 1986; Hicks, 1969), yet the responsibilities and roles within the triad remain ambiguous. Zeichner (2010) has documented repeated need for better training about and increased collaboration between the university and the cooperating teacher. Without such collaboration and unity, there remains a risk of mixed messages, which leaves the student teacher focused on herself rather than dedicated to improving pupil learning. Cochran-Smith (1991) characterized this collaboration as "collaborative resonance," which validates the voice of all participants in the student teaching triad. With this collaboration, the student teaching experience can have an even greater impact on the student teacher's learning than the university coursework.

The role of the cooperating teacher has been long documented with a period of time focusing on improving cooperating teacher efficacy by providing certification (Lingren, 1957). Supporting the cooperating teacher is an important responsibility of a building administrator, according to Conderman and Pedersen (2006). While the building administrator can support the cooperating teacher, the cooperating teacher serves as part of a unique triad: cooperating teacher, student teacher, and university supervisor.

Educational leaders must ensure schools are equipped with staff who can serve all pupils, whatever needs they have. "School leaders' failure to confront the essential question of whom schooling serves and whom schooling does not serve guarantees that 
public schools will not wholly serve all students" (Lindle and Mawhinney, 2003, pp. 45). School leaders must find ways to achieve the true mission of education, leading for the future rather than just managing the present (Bolman \& Deal, 2008).

Connective leadership (Lipman-Blumen, 1996) is comprised of three achieving styles: direct, relational, and instrumental. Direct is the most common, as it resonates of the familiar political and transactional leadership theories. Relational connective leadership focuses on the relationship that develops between the leader and the followers, but also on the relationships that develop among the followers. Instrumental leadership sounds somewhat manipulative, but it is actually a style that incorporates people as tools in work toward goals. The power of connective leadership is in the simultaneity of the three styles. With connective leadership, a leader does not choose just one path; the path is constantly morphing as the needs and circumstances evolve.

The viability of connective leadership is rooted in its ability to be all things to all people at different times. Connective leadership can provide safety and security by being direct. Connective leadership can provide a sense of empowerment by being instrumental. Connective leadership can provide support and encouragement by being relational. The once clear line between adaptive and technical challenges is not as clear in what Lipman-Blumen terms the "connective era" (p. 106). With technology bringing the larger world closer, the need to work with many different people has increased. The effects of technology, like all changes in schools, have been slow to prosper, while the changes in our greater world are quick in this area. Connective leadership provides a model for educational leaders to build the support teachers need to meet the challenges of reforming education. 
Teachers must be reconditioned to feel powerful in schools. In a study of high school teachers, Goddard, LoGerfo, and Hoy (2004) found teachers who believe instruction is helping students achieve ultimately have students who achieve at higher levels because "schools characterized by high levels of collective efficacy communicate a press for effective teaching and learning that yields positive outcomes." High levels of perceived collective efficacy (PCE) are present in "groups [sharing] organizational decision-making powers and... [exhibiting] cooperative behavior aimed at improving...professional practice” (p. 420). Further, according to Goddard et al. (2004), AYP labels should be rephrased in positive terms to increase PCE and, in turn, achievement. Future consideration should be given to analysis of PCE with specific minority subgroups indicated in NCLB data. Teacher perceptions are closely tied to feelings of shared leadership.

It is necessary to clarify the role of instruction in achieving the mission of education in order for public education to survive, let alone thrive.

If the organization's assumptions... are out of line with environmental realities, sooner or later it may face a survival problem. They [organizations] should focus heavily on initial assumptions about the environment ... to validate those assumptions before deciding on goals and means. (Schein, 2004, p. 178)

If these gaps are not able to be overcome, then schools have no purpose, which we know to be untrue. We have a significant gap between what we are doing and what we believe we are working to do (Elmore, 2007). The gap can be overcome; education needs strong connective leaders to bridge this divide.

Standards-based instruction has been gaining momentum in the past decade, led in part by the practitioner-focused research of Robert Marzano and quick reference articles 
of organizations like the Association for Supervision and Curriculum Development: "Standards hold the greatest hope for significantly improving student achievement....But we have yet to systematically enforce or implement standards" (Scherer, 2001, p. 14). But this step alone is not enough to improve instruction in classrooms. Educational leaders must be more collaborative and more systematic in the approach. A clear plan for educational leadership must focus on the following: a clear mission that is shared among all stakeholders and referenced daily as part of the implementation of connective leadership.

Creating the type of professional learning community (DuFour, 2008) that fosters perceived collective efficacy does not come without significant changes to the structural, political, human resource, and cultural frames (Bolman \& Deal, 2008). According to another study, the interaction among teachers outside of the classroom has an impact on the quality of the professional learning community, as well as the teachers' sense of responsibility for the learning of their pupils (Louis, Marks, Kruse, 1996). Schools need building and district leadership that recognizes the importance of this type of collaborative culture.

In addition to recognizing the importance of collaboration, effective school leaders in the $21^{\text {st }}$ century must have the adaptive skills to establish and foster this type of culture. Leaders must also know when to refrain from direct leadership (Greenleaf, 1977) and realize that leadership is dispensable (Selznick, 1957). There are times when leadership will need to take a back seat and let the established collaborative system work.

Cognitive theory (Greenleaf, 1977) labels leaders as being either direct or indirect. In education, some are quick to judge indirect leaders as ineffective. In some 
ways the demands of NCLB necessitate this type of judgment. Annual score increases for age-level rather than cohort student groups diminish the value of incremental and long-term change efforts. Schools and districts that seek long-term improvements based on incremental changes, such as fiscally conscious staff development that uses the "trainthe-trainer" model, are doomed to labels of failure. Leaders attempting to improve schools over time are likely to be judged as ineffective when really they are just longterm and indirect leaders. Indirect cannot be allowed to become synonymous with inactive. Indirect leaders need to identify short-term gains that will allow employees to see the benefits of their immediate work.

Conderman and Pedersen (2006) provide practical tips for building administrators with regard to student teaching placements. In Conderman's work with other researchers, he effectively analyzes several critical studies as the literature base for his own research. Conderman and Pedersen's 2006 article, though not peer reviewed and scholarly in nature, begins to bridge the gap between research on effective student teaching placement climates and the roles of those traditionally involved during the student teaching placement: cooperating teacher and university supervisor. These two main factors, climate and participant roles, are brought together in Conderman and Pedersen's recommendations for administrator actions. In their 2006 article, Conderman and Pedersen suggest steps principals and other building leaders can take to improve student teaching as a whole in response to a gap in literature they identify: limited student teaching research resulting in directives for administrator action. One of the 2006 suggested administrator actions, the suggestion for administrators to partner with the cooperating teacher, supports the importance of the cooperating teacher's role. 
With the importance of the role of the cooperating teacher, it is important to explore the selection process for identifying cooperating teachers, specifically the role of administrators in this selection process. Inspiration in the form of energy and ingenuity are not enough for a student teacher to find success, though. Critical other components required for achieving success are provided by the cooperating classroom teacher. This person provides the practical knowledge that cannot be gained from book study and mock lesson delivery. This practical application merges together instructional delivery with classroom management savvy, what Danielson outlines in Domains 2 and 3 (Danielson, 2007). The management toolbox of a cooperating teacher is expected to far exceed that of a typical student teacher, and this "thinking on your feet" is the exact skill that can only be learned in a real school setting with real pupils.

Responsibility for success of such a placement does not fall squarely into any one place: It the responsibility of the college or university to find a quality placement, and it is the responsibility of the school district to ensure the placement is high quality. There must be a symbiotic relationship (Goodlad, 1999). Responsibility for a successful student teaching experience falls on multiple partners: college or university supervisor, student teacher, cooperating teacher (classroom teacher), and the building and district administration. Without cooperation among all of these individuals, the student teaching experience will not be a success for the student teacher or for the pupils being served. It is in the student teaching experience that the study becomes reality, as the focus for the student teacher is transferred from success for teacher to success for pupils (Webber, 1994).

Preparing future teachers to work with children is a privilege, but, like other privileges, it comes with responsibilities. Though student teaching requirements have 
changed slightly over time and still vary somewhat from school to school, the core responsibility remains the same: learn to do the job — and all it entails — of the classroom teacher (Butterweck, 1951). Administrators coordinate the school's responsibilities; university supervisors coordinate the university's responsibilities.

With consideration typically given to the interests and preferences of the cooperating teacher and the student teacher, this study and its accompanying research highlight the importance of administrators taking an active role in identifying who should be a cooperating teacher. Student teaching is the culminating application of content and pedagogical studies; it serves as the full-time opportunity for future professionals to apply theories and research in a true-life setting with students who respond as individual learners. While many professions include a pre-employment internship, few other new professionals are expected to achieve the same level of independent work necessary of a first-year teacher.

An increased focus on standards in education has moved beyond standards for teachers and students. The focus on standards is now evident in the teacher preparation programs due to the strong influence of the National Council for Accreditation of Teacher Education (NCATE), following the lead of the Holmes Group that initiated Professional Development Schools. NCATE has identified a vision for the future of teacher preparation that includes clearer and more consistent guidelines for pre-clinical and student teaching experiences. The stronger guidelines reconsider the role of the cooperating teacher, noting this individual's responsibilities need to be more closely aligned with the efforts of the higher education teacher-training program. The demand for improved alignment reinforces the value of research on what is and is not working in 
current alignment efforts.

Focusing on the benefits and challenges of standards-driven improvement efforts, Yinger and Hendricks-Lee explain that standards, when developed properly, empower organizations from within by strengthening those involved in the system. These researchers stress that standards provide the public and those involved in the system with what Yinger earlier termed "language of practice" (1987). The challenge, conversely, is that such a public language can sometimes be misused in attempts to externally control the system. Such external control can be damning to a system if those attempting control have limited knowledge and expertise beyond the shared language. With their argument for how standards add to professionalization, my own analysis regarding the analysis of factors in selecting cooperating teachers is strengthened. Without standards for the selection of cooperating teachers, the system is lacking legitimization.

"Meaningful school reform requires revising institutional climates, including organizational structure and culture" (Kowalski, 2006, p. 48). This type of revision to a culture will take time and carefully coordinated efforts. To achieve the necessary changes, it is critical that superintendents work through specific strategies to identify "what individuals and groups truly believe and value about education" (Kowalski, 2006, p. 49). The superintendent then directs her team to coordinate the implementation of those community-desired changes.

Too often, schools only use teacher leaders as part of the popular "train the trainers" model or as interns pursuing future administrative positions. Redefining how we view teacher leaders will provide opportunities for teachers to be student advocates in a new way. Schools surely benefit from more "principle-centered" rather than "principal- 
centered" leadership (Covey, 1990). Activating potential within teachers and pupils is critical to connective leadership.

As part of this interdependence, teachers need to be involved in planning and implementing staff development that is tailored to individual teacher needs. Teachers are the "street-level bureaucrats" (Weatherly \& Lipsky, 1977) who will be the true determination in the success of any educational reform efforts. Beyond the planning stage, teachers need to be well informed of how the information gathered through the various phases of staff development will be used to plan future staff development and also to make decisions for the district as a whole. As professionals, teachers need to be afforded opportunities to build their capacity and to be active within their profession (Elmore, 2002a, 2002b). Building this capacity means increasing the potential of the overall staff through hiring practices and staff development efforts, focusing existing capacity on specific goals or populations, and mobilizing existing capacity so its full potential is realized through shared decision making and other collective efforts (Corcoran \& Goertz, 1995). Teachers need to know that information gathered by school leaders during staff development will contribute to building administration decisions, showing teacher input to be highly valued.

Teachers are beginning to view leadership more collaboratively (Boyd \& McGree, 1995), though they may not have all of the skills to effectively participate in the leadership conversations. With staff members viewing leadership as more of a group process than an individual's decision, changes within the structure of a teacher's workday and staff development plans must be made to include this more shared view, a view where leadership is distributed among several groups. In the distributed leadership 
perspective, leaders interact with one another fluidly rather than in a hierarchical manner: "Individuals play off one another, creating a reciprocal interdependency between their actions" (Spillane, 2006). Previous efforts to lead only through connection have not been successful because the relational aspect of leadership needs the direct and instrumental aspects for balance.

The type of collaboration that will be necessary to reform schools will require tighter coupling of our traditionally loosely coupled schools (Weick, 1976). In loosely coupled systems, various components are only connected to one another in very limited ways. In tightly coupled systems, there are more permanent interdependencies. There are four specific characteristics Weick (1982) identifies for labeling a system as tightly coupled: rules, agreement on rules, system of evaluation for compliance to the rules, and feedback to lead to greater levels of future compliance. Weick explains that there are advantages to loosely coupled systems. Such systems are protected from being unsettled by minor changes in their external environment; they also allow for major changes to occur within certain components of the organization without changing the entire system. Problems in loosely couple systems can be more easily isolated, and individuals can benefit from a stronger sense of autonomy.

While such a picture creates a positive view of loosely coupled systems, having schools function in this way has not proven beneficial for pupil achievement. Unfortunately, it is terribly difficult to bring about major philosophical change in a loosely coupled system, so the changes needed in schools will not be easily made. As noted in Weick's (1982) article, "Administering Education in Loosely Coupled Systems," these types of systems are not easily changed on a large scale. It is assumed in a loosely- 
coupled system that large-scale change is seldom needed because it will be selfregulating. However, schools have not been self-regulating; instead, they have been plagued by “coercive isomorphism” (DiMaggio \& Powell, 1983, p. 150) wherein schools are beginning to look more and more like one another without actually improving. The entire system of instruction needs to be more closely connected to the research and policy that evaluates and monitors that instruction. Instead, schools have been responding to external pressures from various political groups, which has resulted in organizations that have lost their mission and only have a formal structure that is actually based on myth (Meyer \& Rowan, 1977).

Having all of the right components of a change initiative will not guarantee the success of the initiative, but the lack of key components, such as having teachers be morally engaged in the process, will surely lead to failure (Fullan, Cuttress, \& Kilcher, 2005). Professional learning will need to address the lack of "instructional program coherence" (Newmann, Smith, Allensworth, \& Bryk, 2001) far too prevalent in schools. Leaders in Illinois schools and districts have an opportunity to be connective leaders with the evaluation reforms already begun. The loosely coupled school environments which administrators and policy have failed to address have led to a system wherein curriculum, instruction, and assessment are separated from school leadership. The new evaluation tool and process needs to be tightly coupled in a positive way with instruction, teacher culture, and leadership.

Building administrators can also be instrumental in the coupling process, with principals and their designees sharing necessary resources to help cooperating teachers partner effectively with student teachers (Babkie, 1998). Connective leadership can use 
cooperating teachers as instruments of reform for the school in addition to the student teacher through partnerships with teacher preparation program.

\section{Training and Certification Program Expectations}

While some argue certification of teachers makes little to no difference, evidence of the effect of teachers on student learning would suggest by transfer that the training provided to the teacher makes all the difference. Horowitz, Darling-Hammond, and Bransford (2005) highlight the need for more complex teaching, with teachers being more responsive to the pace of an individual pupils' learning. Teacher preparation programs are conversely returning to older factory models. Reform history has shown that those models were not successful for pupils in schools, so to suggest that those models would be a good fit to serve teacher preparation is impractical. Further, with teachers naturally gaining some of their knowledge of teaching through their own experiences, it would be a disservice to pupils to train teachers in this way.

There are specific, though inconsistently employed, steps to assist with improving training and certification programs. Several of those steps, as they relate to a richer view of the signature pedagogy for teaching, will be discussed.

Support for the triad. The communication and cooperation among the student teaching triad (student teacher, cooperating teacher, and university supervisor) is traditionally weak. "Cooperating teachers are a vital partner, role model, and mentor. In fact, student teachers attribute most of their dispositions and instructional practices to their cooperating teacher rather than their university preparation" (Richardson-Koehler, 1988). Cooperating teachers provide support in classroom management and content instruction (Grossman \& Richert, 1988; Bozella, 2008). Though this role is vital, no 
training is provided to the cooperating teacher (Zeichner, 2010). These issues are evidence of a loosely coupled system (Weick, 1976).

Several ongoing issues are common with student teaching placements (Guyton \& McIntyre, 1990). These issues compound an already stressful yet critical time in the development of the student teacher as a professional. Commonly identified issues relate to communication and unclear expectations. While not noted by these authors, these issues could be addressed early on with a more structured student teacher placement and cooperating teacher selection process.

Criticism of current literature argues most analysis has not investigated the roles of all three triad members, usually focusing on only one or two (Guyton \& McIntyre, 1990; Valencia, Martin, Place, \& Grossman, 2009). These researchers reinforce the complexity of the relationship between cooperating teacher and student teacher. This limitation of the perception research is similar to my own identification of the gap in the literature on the role of administrators in the student teaching placement process.

The student teaching triad really exists within the larger context of the school and within the field of educational policy. The traditional triad could really be thought of as a team of four or five rather than the isolated vision of the three musketeers. One of the primary areas of lost learning is the missed mentoring beyond that provided by the cooperating teacher. The importance of this type of support and critical friend sharing is also noted in another primary area of lost learning: limited feedback on subject matter teaching ability and base knowledge.

Partnerships with schools. To save the teacher preparation programs, required certification must be examined more deliberately (Boyd, Grossman, Lankford, Loeb, \& 
Wyckoff, 2009). Effective programs will not be replicated by chance. DarlingHammond (2010) highlights the importance of what she coins "expert guidance" during these pre-teaching practice experiences. Such a focus supports the important role of the cooperating teacher in a student teacher learning to be effective. Her recommendations go one step further in suggesting universities partner with schools to improve the quality of the overall school in which pre-service teachers will be placed.

Darling-Hammond (2010) believes such efforts begin with partnerships between universities and schools, and she decries government for not requiring teacher education programs to be of more consistently high quality, even if that means providing financial support to programs and beginning teachers. Additional research (Borko \& Mayfield, 1995; Babkie, 1998) notes the role a cooperating teacher can play as a role model for student teachers, but the specific qualities that cooperating teachers would be expected to model are not outlined officially nor are the traits a cooperating teacher would be expected to have, beyond some type of perceived master teacher status through the eyes of a building administrator. Further, the responsibility for selecting cooperating teachers falls entirely upon the district, with the universities assuming qualified teachers are being selected to fulfill this critical role. Improved partnerships between universities and schools would address this second example of loose coupling within the student teaching process of the signature pedagogy for teaching.

In public education, there is a need for transformational leadership in a more adaptive form: connective leadership (Lipman-Blumen, 1996). Connective leadership will have the greatest impact on the instructional core (Elmore, 2007) and-consequently - pupil achievement. The school environment must transform from a workplace focused 
on adults to a learning environment focused on pupils (Rosenholtz, 1989). Connective leadership can provide support for the development of more distributed leadership. Teachers would be supported to move beyond their current culture to collaborate in building and constantly adjusting their propositional, case, and strategic knowledge. Such support would enrich the development of signature pedagogies for teaching that are aligned with a clear mission for schools and buttressed by relationships with university partners and strong cooperating teachers. Instructional practices must move away from an isolationist view to a more productive learning community in which teachers view their work more clinically in partnership with one another and with administrators. Teacher evaluation and the training of pre-teachers must value all types of interpersonal and content knowledge required of teachers inside and outside the classroom, as well as specific strategies for determining how and when to apply such knowledge.

Leadership will need to be connective and to bring together what Shulman (1987) describes as "streams of inquiry" (p. 266). The streams of inquiry are the two paths of theory and practice. Incorporating these two lines of thinking and questioning into teacher training and educational leadership will provide the shared knowledge that will lead to policies and practices that are best for pupils.

\section{Summary}

The role of the cooperating teacher is absolutely invaluable, so the way in which these individuals are chosen is critical. The study outlined in the next chapter will explore the traits administrators consider most important in the selection of these valuable individuals: cooperating teachers. 


\section{CHAPTER III}

\section{METHODOLOGY OF THE STUDY}

The study investigated the traits high school administrators perceived to be most important in selecting cooperating teachers, with consideration given to their perception of the selection process overall; there was a specific focus on how the dominant traits identified by participants aligned with Danielson's (2007) Framework for Effective Teaching. Teachers are the most important factor in student achievement, so the selection of individuals who train student teachers is critical. Research has shown the student teaching placement process is a process that is fraught with role confusion and disconnectedness between theory and practice. The following chapter includes a review of the research questions and a description of the research procedures applied in this study. These sections are followed by a narrative of the appropriateness of qualitative techniques for this study, as well as a report of how the data were collected and analyzed.

\section{Research Questions}

The research questions for this study reflect a desire to better understand the dominant teacher traits administrators seek in placing student teachers. This study explored the following research questions:

1. How do administrators describe the process for selecting cooperating teachers in core content areas at the high school level?

2. What professional qualities do administrators consider most important in the selection of high school core content area cooperating teachers? 
3. What instructional qualities do administrators consider most important in the selection of high school core content area cooperating teachers?

4. In what ways, if any, do administrators' perception of a staff member within the department, building, or district influence the selection of that individual as a cooperating teacher?

5. What evidence do high school administrators use in selecting and reviewing the effectiveness of cooperating teachers? How does this evidence align with the Danielson (2007) Framework for Effective Teaching?

\section{Research Procedures}

A qualitative research approach was applied in this study. Van Manen (1990) notes that this type of design focuses on individuals" "lived experiences" (p. 9). The qualitative method was chosen to focus on the perceptions of the participants, specifically seeking to elicit rich descriptions. More specifically, a case study design was employed to further explore participants' views by school district. According to Merriam (2009), "a case study is an in-depth description and analysis of a bounded system" (p. 40), the bounded system in this study being a specific school district. Choosing the qualitative case study provided a clear picture of some of the perceptions within that district, a picture that would not be possible with a quantitative study. The case study model was suitable for this study because it showed the real life of the districts examined. The use of a qualitative study allowed for increased understanding of the phenomenon within the natural environment.

Participants in the study were selected initially based on their district's involvement with the Consortium for Educational Change, indicating an awareness of the importance of improving teaching through all possible avenues, including improving the training of pre-service teachers through the intentional collaboration of teachers and 
administrators. This selection narrowing provided for information rich cases to study in depth (Patton 2002). To further narrow the pool for this study, purposive sampling was used to select the eight unit districts labeled by the Illinois Interactive Report Card as large suburban districts of Chicago. Once these schools were identified, three districts were selected by random sampling to represent the final sample of participants for this study. The sampling was narrowed to this size to develop a more manageable sampling size.

A total of five administrators representing three districts were sought to participate in one-on-one interviews. In the case where a particular district had more than one high school, convenience sampling was used to select an administrator from an individual school building for the interview. Within that building, the assistant or associate principal focusing on curriculum and instruction was asked to serve as one of the participants. The selection of the department chairs was done through random sampling at each of the identified buildings, selecting one department chair from science, math, or English at each of the participating high schools. Efforts were made to select a variety of department chairs, attempting to represent all of these areas with the selection of participants.

Because the data represented individuals' perceptions, the conclusions may not necessarily be generalized to other districts. However, by identifying participants from districts similar in size and only high schools, some patterns may emerge about the practices of placing student teachers in high schools in large suburban districts in Illinois. The case study format used here was a comparative case study, as the information from three districts will be analyzed separately and in relation to one another. 


\section{Research Ethics}

An effort was made to ensure that the potential for physical, psychological, or social risks in this study was minimized. However, some participants may have felt that comments on their district's student teacher placement practices may be shared with their administrators and negatively affect their employability. Institutional Review Board approval was sought prior to data collection as required to further safeguard potential risks were identified and minimized. Further, confidentiality was maintained throughout the data collection, analysis, and writing process by ensuring all materials were kept in a locked, limited access cabinet at the co-principal investigator's home and by using pseudonyms when referring to study participants. Participant pseudonyms were based on color, with related colors representing individuals within districts: blue and purple, red and pink, as well as yellow. Only the principal investigator and co-principal investigator had access to the confidential information. Participants were also encouraged to select the interview locations to maintain the level of privacy and discretion they desired. Because the risks of this study were minimal, the opportunity to reflect on one's practices and contribute to a study in the field of education outweighed any potential risk.

\section{Qualitative Techniques}

In qualitative research, experiences are not so much discovered but shared, with the focus of qualitative research being on developing an understanding of what Merriam (2009) describes as "how people interpret their worlds" (p. 5) and "how people make sense of their lives" (p. 24). Qualitative research is used to create a description of people's perceptions of their roles and others' roles within an experience. In order to ensure limited bias, the researcher of this study also considered her own responses to 
each interview probe prior to beginning the interviews, as a form of epoche, defined by Moustakas (1994) as a process whereby “everyday understandings, judgments, and knowings are set aside, and the phenomena are revisited" (p. 33). By pre-identifying my own responses, I was more aware of setting aside these responses rather than inadvertently superimposing them onto the data analysis.

The semi-structured interview process provided structure without stifling the flow of the interview (Merriam 2009). The interviews were designed to last no more than 60 minutes and included various types of questions. There were experience and behavior questions, opinion and values questions, knowledge questions, and background and demographic questions (Patton 2002). In addition to the semi-structured interview probes (Appendix C), there were two activities: Selecting a cooperating teacher and Ranking Cooperating Teacher Qualities (Appendix D).

Merriam (2009) notes five particular qualities of a semi-structured interview; they are as follows:

1. Interview guide includes a mix of more and less structured interview questions. 2. All questions used flexibly.

3. Usually specific data required from all respondents.

4. Largest part of interview guided by list of questions or issues to be explored. 5. No predetermined wording or order. (p. 89)

All but the last quality were followed in this study. The wording of interview probes was expected to vary from interview to interview, but the order of the questions was maintained in each interview. This was an intentional decision to ensure that the same depth of data would be gathered from each participant. Changing the order of the questions may have prompted individual respondents to respond more or less fully to some questions than their colleagues, depending upon their placement order within the 
interview. Regardless of the order of the questions, each participant was asked to respond to the two same closing questions, "Is there anything else that you want to add about anything that we've talked about today? May I contact you again to follow up on this interview?"

Documents related to the student teaching placement process, as they were available from the participants, were also requested for review. These documents were expected to include criteria for the selection of cooperating teachers, board of education policies related to student teacher placement, university partnership agreements, and the like. Documents are more stable than individual participant responses, though they may have shortcomings in that their original source may not be known and their chain of custody may also be questionable (Merriam, 2009). While it was expected that there may have been no documents available in some districts, or the documents may have provided little if any detail about the criteria for selecting cooperating teachers, this lack of information would be considered to be a source of data in itself: "If no documents exist, however, or if the documents are sparse and seem uninformative, this ought to tell the inquirer something about the context" (Guba \& Lincoln, 1981, pp. 234-235).

Beyond the traditional interview probes and document analysis, participants completed two activities during the interview: Choose a Cooperating Teacher (CT) (Appendix D) and Trait Sort (Appendix E).

During the Choose a CT activity (Appendix D), participants were given three laminated descriptions of potential cooperating teachers, and they were asked to identify which individuals, of the three described, they would consider selecting as a cooperating teacher. Participants were asked to describe the reasoning for selecting and not selecting 
Mr. X, Ms. Y, and Mrs. Z. The descriptions were comparable in that they all included the amount of time the individual had been teaching, the perceptions of students, and highlights of that teacher's professional practice. None of the descriptions included specific details about the individual's use of assessments or instructional practices. These details were intentionally omitted to determine if participants would indicate an interest in such information, as all participants were asked if there was any additional information about the potential cooperating teachers that they would have liked to have had when making their decision.

During the Trait Sort (Appendix E), participants were given 11 laminated strips, each listing a component of Danielson's FfET (2007). There were three components from Domains 1, 3, and 4, and two components from Domain 2. The traits were not labeled as being part of Danielson's FfET when used during the interview activity; they were also not labeled with their corresponding domain when used during the interview activity. Participants were asked to sort the traits according to the three traits they considered to be most important and the three traits they considered to be least important, from the traits provided.

The traits were selected from among the 22 components of Danielson's (2007) FfET for a variety of reasons. The components selected as traits from Domain 1 were selected because of their applicability across disciplines, having reasonably consistent need for these traits in the areas of English, Math, and Science, the content areas selected for this study. These traits were also selected because of their consistency in being the knowledge pieces within Domain 1. The traits selected from Domain 2 were selected for their consistency if focusing on management, providing a clear highlight of this domain 
as being more focused on structures and systems rather than the instruction and learning occurring within those structures and systems.

The traits selected from Domain 3 were selected as being distinct while encompassing the other traits from this domain that were not selected. Specifically, the trait related to questioning may have been difficult for participants to distinguish from the trait regarding communication with students without the additional rubric from Danielson's (2007) framework. As the application of the traits rather than a review of them compared to one another was the focus of the study, these traits were selected to represent this domain. In Domain 4, traits were identified to represent the major areas within this domain: reflection, communication, and professionalism. Three of the components from this domain were combined into the trait of "Participation in professional growth and school improvement." This provided for clarity for the qualitative study participants when ranking traits, so as not to conflicted about the sorting of traits very similar to one another

An increased focus on qualitative research is supported within the social sciences (Kennedy 2008, Maxwell, 2004) because of its reflection of the experiences that are truly represented by the multitude of variables that simply cannot be separated, specifically in an educational setting. The qualitative researcher assesses symbols "to record the pattern of responses these symbols elicit" (Van Manen, 1979). The patterns that may be identified through these interviews may be patterns within the individual school buildings, the roles of administrators, or the high school level as a whole, with the interview being used to develop a type of conversation between the participants and the researcher. The intention was to develop a "conversation with a purpose" (Dexter, 1970, 
p. 136), that purpose being to gather information that would otherwise only exist in the unspoken thought process of the school administrators as they select cooperating teachers (DeMarrais, 2004).

\section{Research Positionality and Reflexivity}

This topic is of particular interest to me both professionally and personally. I have worked in education for 16 years: 7 years as a full-time high school English teacher, 5 years as a department chair, and 4 years as a building administrator who is responsible for the placement of student teachers in my building. I have worked in a large suburban unit district, which is why I chose this type of district as the focus for this study. I have participated in dozens of student teaching placements, including serving myself as the cooperating teacher for four student teachers and multiple clinical students. In my role as a building administrator, I have seen varying levels of success of the student teaching triad, with a great deal of emphasis always placed on the fit of student teachers and cooperating teachers.

As an educator, regardless of the particular position I currently hold, I have a great deal of respect for the work of classroom teachers and for the importance of the work of all those involved in their training. To minimize any biases I have toward defending the work of teachers, the interview questions were structured as open ended rather than leading. The activities incorporated into the interview were also designed to gather a variety of expansive responses rather than particular shorter responses that I might identify as matching or not matching my own experiences. To further avoid any conflicts, no interviews were conducted in my school district. 


\section{Data Analysis}

Merriam (2009) clarifies that data analysis is best accomplished when it is completed alongside data collection. The process of analysis is ongoing. Transcriptions of the interviews were coded by continually reading the transcriptions and "looking for recurring regularities in the data" (Merriam, 2009, p. 177). Because of the case study design of this study, transcriptions, field notes, and participant profiles were all brought together, with key ideas being identified. The initial first cycle process used was open coding, with all information that seemed noteworthy being commented on in the margins of the transcripts.

Following open coding, the second cycle process used was values coding, where the participants' values, beliefs, and attitudes were noted (Gable \& Wolf, 1993; LeCompte \& Preissle, 1993). This method was chosen as a means of exploring participants' "cultural values, identity, intrapersonal experiences, and interpersonal experiences" (Saldana, 2013, p. 111) to better understand perceptions of which factors high school building administrators and department chairs were determining the selection of cooperating teachers.

The second cycle coding results were reviewed for patterns and also reviewed through the lens of Danielson's (2007) Framework for Effective Teaching (FfET). The variables identified by the participants were partitioned rather than integrated (Miles, Huberman, \& Saldana, 2014). When reviewed through the lens of the FfET, participants' values, beliefs, and attitudes were compared to the various domains, with a focus on determining if the predominance of values, beliefs, and attitudes determining the selection of cooperating teachers aligned with domains related to instructional planning 
and delivery (Domains $1 \& 3$ ), domain related to classroom management and the learning environment (Domain 2), or the domain encompassing other professional characteristics (Domain 4).

\section{Ensuring Reliability and Validity}

To ensure reliability of the data analysis, the interview probe data were triangulated with information gathered from the institutional documents and participant responses from the activity components. In addition, the interview data were transcribed, coded, and themes generated through the lens of the Danielson framework. In Chapter IV, the data will be presented in two formats: according to the primary research questions, including comparative case studies of the three districts' administrator views of the process and factors relevant and in the selection of cooperating teachers. The data will also be analyzed through the domains of Danielson's (2007) FfET.

\section{Summary}

From the data collected, themes were identified. The themes that were identified were intended to gather the transcribed interviews into groupings to make meaning of the participants' lived experiences (Merriam, 2009). The study described the factors high school administrators perceived to be relevant in placing student teachers within the using the lens of the Danielson's (2007) FfET. 


\section{CHAPTER IV}

\section{ANALYSIS OF RESULTS}

\section{Introduction}

The purpose of this study was to describe the factors perceived relevant in administrator selection of high school cooperating teachers, using values coding, resulting in a culture picture. Qualitative research techniques were used, including semistructured interviews with five participants. This chapter will report the themes from the data, organized by the research questions, and then present a summary analysis of the results through the lens of Charlotte Danielson's (2007) Framework for Effective Teaching. The chapter will close with a summary of the most significant patterns from the participants' responses.

\section{Participant Profiles}

The participants of the study were department leaders (department chairs or division coordinators) and building administrators (assistant principals or associate principals) involved in the student teaching placement and cooperating teacher selection process in three large unit districts in the suburbs of Chicago, Illinois (see Table 2). To ensure the anonymity of all of the participants and for clarity, individuals functioning in the department leader role will only be referred to as department chairs in these research results, and individuals functioning in the building administrator role will only be referred to in these results as assistant principals. All of the participants were licensed 
educators in Illinois. All but one of the participants student taught prior to beginning his or her career in education; one participant was alternatively certified through a program that did not require student teaching.

Table 2

Study Schools and Participants

\begin{tabular}{lll}
\hline High School & Assistant Principal & Department Chair \\
\hline Teal High & Mr. Blue & Mr. Purple \\
Magenta High & Mr. Red & Mr. Pink \\
Gold High & Mrs. Yellow & \\
\hline
\end{tabular}

Prior to securing agreement from these five participants, email invitations and follow-up phone call invitations were extended to participants in other districts. For one of the other districts, there was an agreement from a department leader to participate but not from the building administrator. For two other districts, there was no response from either the department leader or the building administrator. Ultimately, participation agreement was secured from the three participating districts, with a building administrator from each district participating and a department leader from two of the three districts participating.

\section{Participant \#1}

Mr. Blue is an assistant principal; he coordinates student teacher placements for the school, working closely with the department leaders. In this capacity, he approves student teacher placements and cooperating teacher selections for all content areas, in addition to overseeing staff development and testing. Prior to beginning his career, he 
did not student teach; he was certified through an alternative certification program which, he explained, is no longer an option in Illinois. He has held the position of assistant principal at this building for more than 5 years and indicated a very strong interest in the topics of student teacher placement and cooperating teacher selection.

\section{Participant \#2}

Mr. Purple is a department leader for science; he coordinates the student teacher placements for the department, working closely with the assistant principal, Mr. Blue. In this capacity, he coordinates the approval of all student teacher placements and cooperating teacher selections in science and technology courses. He has held the position of department leader at this building for more than 4 years.

\section{Participant \#3}

Mr. Red is an assistant principal; he coordinates student teacher placements for the school, working closely with the department leaders. In this capacity, he approves all student teacher placements and cooperating teacher selections, in addition to overseeing the work of the department leaders. He has held the position of assistant principal at this building for 1 year; prior to this, he was a department leader in a high school of similar size in another nearby district.

\section{Participant \#4}

Mr. Pink is a department leader for English; he coordinates the student teacher placements for the department, working closely with the assistant principal, Mr. Red. In this capacity, he coordinates the approval of all student teacher placement and cooperating teacher selections in English, social studies, and world languages. He has been in this position of department leader at the building for 2 years; prior to this, he was 
a department leader in a high school of similar size in another district.

\section{Participant \#5}

Mrs. Yellow is an assistant principal; she coordinates student teacher placements for the school, working closely with the department leaders. In this capacity, she approves all student teacher placements and cooperating teacher selections, in addition to overseeing all areas of curriculum and instruction for the school. She has held the position of assistant principal at this building for 2 years; prior to this, she was an assistant principal at an elementary school within the same district.

The participants were chosen because of their assigned roles, which require specific involvement in the cooperating teacher selection and student teacher placement processes. All participants had a personal knowledge of the structure of the processes and the specific steps within their school buildings.

\section{School Profiles}

\section{School \#1}

Teal High School, the school where both Mr. Blue and Mr. Purple work, has an enrollment of just over 2,000 pupils in grades 9-12. There are approximately 150 certified teachers, and the school regularly hosts student teachers. During a typical year, they host 1-2 student teachers in science and English; they are not currently hosting student teachers in math due to changes in the math curriculum.

\section{School \#2}

Magenta High School, the school where both Mr. Red and Mr. Pink work, has an enrollment of just under 2,000 pupils in grades 9-12. There are approximately 140 certified teachers, and the school regularly hosts 1-3 student teachers in each department, 
though recently their number of student teachers has declined as they have been working on various curricular shifts.

\section{School \#3}

Gold High School, the school where Mrs. Yellow works, has an enrollment of just under 1,700 pupils in grades 9-12; the ninth grade pupils attend a freshman campus near the main high school campus. There are approximately 115 certified teachers, including the teachers at the freshman campus. The school regularly hosts student teachers, typically having 1-2 student teachers in math, science, and English in a given school year.

\section{Research Issue}

This study was conducted in order to investigate the dominant factors the administrators selected from the schools believed to be relevant in selecting particular teachers to serve as cooperating teachers in their districts. It also focused on how the cooperating teachers were selected, as their particular characteristics reflect the factors considered relevant in student teacher placement. For example, a cooperating teacher requirement such as tenure status would reflect a certain level of experience as relevant in the student teacher placement process.

\section{Results}

\section{Research Question \#1}

How do administrators describe the process for selecting cooperating teachers in core content areas at the high school level?

From the research interviews, four main themes evolved describing the process of selecting cooperating teachers: process rather than task orientation, collaborative conversations, designated roles of participants, and the importance of individual 
preferences and perspectives. Participants all suggested a common strand of "fit" within the process, with various attempts to articulate this term concretely. The interview probes asking about the participants involved in the cooperating teacher selection and student teacher placement processes, as well as those inquiring about participants' satisfaction with the process, elicited much of the evidence for this research question.

Process rather than task. Most of the respondents labeled the selection as being process rather than task oriented; however, that was not the case with Mr. Red who stated directly, "I don't think there's a process; I think it's literally...gathering interest for who wants to be a cooperating teacher for next year." His description differed from the other participants, who all described the selection of cooperating teachers as more of an ongoing process.

Respondents all described the selection of cooperating teacher as a process that involved multiple conversations, most commonly between potential cooperating teachers and department chairs. The conversations were two-way, in that the department chairs were seeking volunteers and willing participants to serve as cooperating teachers. The "selection" was process oriented, as opposed to a one-step request and agreement, with Mr. Red mentioning multiple steps: "talk with the department chairs... look at the resumes [of student teachers]...look at the information." The conversation and process was not described as sequential by any of the participants. A distinct step-by-step process was not outlined by any of the participants.

Despite commonality in describing the selection as a process, the true extent of this process was unclear, as all of the participants mentioned the "process" involved phases and details that were unknown to them, such as the responsibilities fulfilled within 
the district-level human resources department. Though the human resources department was mentioned, there was no evidence cited about that department playing a role in recommending or dissuading the selection of particular cooperating teachers; the work of the human resources department generally referred to approval of the student teachers.

Despite some of the process being unknown, all respondents offered compliments to the structure followed at their building and district. There was, conversely, significant criticism about the role of the university in the placement of the student teachers. The concerns raised did not acknowledge any opportunity for the universities to play a larger or different role in the selection of the cooperating teachers, but the comments focused on the universities doing more to assist in the effective placement of the student teachers. There was no mention by any of the participants that an improvement of the placement could be related to the selection of the cooperating teachers.

Even with the criticism of the university's role in this parallel process, all participants were satisfied with the overall process for selecting cooperating teachers, placing great value on the level of site-based decision making afforded as part of the process. There were numerous comments about the intimate knowledge department chairs have of their staff, with those comments being used to argue the importance of the department chairs, in turn, being the individuals to have the final decision of who will serve as a cooperating teacher.

Collaborative conversation. The process was described as overwhelmingly collaborative and conversation-rich by all of the participants, with each of them noting the importance of communication and discussion with multiple stakeholders throughout the processes of both selecting cooperating teachers and placing student teachers. The 
collaborators involved in the process included the building administrator, typically the assistant or associate principal overseeing curriculum and instruction, the department chair or division coordinator, and the potential cooperating teachers. Mr. Blue noted the process typically begins with either an announcement or email to the department seeking volunteers.

This invitation format was echoed by Mr. Red and Mr. Pink. In contrast, Mrs. Yellow and Mr. Purple described processes that began with a type of brainstorming of potential cooperating teachers. For Mrs. Yellow at Gold High, the collaboration began with the principal and assistant principal discussing potential cooperating teachers within the department being considered for potential student teacher placement. This conversation then reportedly carried over to a private conversation between Mrs. Yellow and the department chair. During this discussion, Mrs. Yellow pronounced these potential cooperating teacher names as "cards in my back pocket," that could be mentioned to the department chair if the department chair did not otherwise offer those names as potential cooperating teachers.

Interestingly, Mr. Purple felt the process of selecting cooperating teachers began with the department chair talking with specific potential cooperating teachers, gauging their interest and encouraging their participating. However, the assistant principal at that same Teal High School, Mr. Blue, felt the process of selection began with an invitation to all department members. Regardless of which step typically occurred first, both participants from Teal High, as well as all of the other participants, described some type of face-to-face conversations happening as part of the process for selection of cooperating teachers. 
For participants who noted the volunteer invitation occurring first, specific comments were shared about the importance of sorting out which volunteers were truly viable cooperating teachers. Mr. Pink clearly stated that 'I'm like okay. I don't care if they said yes; I'm not even gonna give it because that kid's not gonna really get anything necessarily from it." The kid to whom Mr. Pink was referring was the student teacher, and Mr. Pink went on to explain that if a volunteer had inadequate instructional practices, then that volunteer would not be selected as a cooperating teacher. Mr. Red, assistant principal at Magenta High, suggested that some teachers may volunteer to serve as a cooperating teacher for unacceptable reasons, indicating that the department chair "knows the true reasoning behind taking a student teacher."

The collaboration and conversation involved in selecting cooperating teachers, though occurring in different formats and on different timelines, repeatedly included multiple candid conversations.

Designated roles of participants. All of the participants discussed the importance of individual roles and responsibilities, focusing most specifically on how these roles effect the student teacher rather than the cooperating teacher. All participants mentioned the role of the district-level human resources department in ensuring the student teacher had the required documents completed for the university and personnel screening. They summarized the responsibilities in ways similar to Mrs. Yellow, who stated simply, "I send them [the student teachers] to human resources to make sure that they've got everything that they need paperwork wise.” Mr. Blue explained that after all of the paperwork is submitted to human resources the building and department leaders know "everything's okay." Based on the general tone of their responses and the lack of 
detail, none of the participants understood the specific responsibilities fulfilled by the human resources department.

The specific responsibility consistent among all of the participants was the use of an interview of the student teacher, involving the cooperating teacher and the department leader. This was referenced by Mrs. Yellow and Mr. Pink, with Mr. Pink giving the potential cooperating teacher "full veto power," because it is ultimately the cooperating teacher whose "voice needs to be heard the loudest." The department chairs and assistant principals reinforced the importance of the cooperating teacher's involvement in placing the student teacher.

Mrs. Yellow also noted the importance of the cooperating teacher in being a "fit" with the student teacher. This fit concept was reinforced by all of the participants, with phrases such as "similar philosophies" used to describe this fit. Mr. Red outlined the steps in his process in this way:

There are a bunch of criteria that you [the cooperating teachers] have to meet... We have a running list... of people...interested in being cooperating teachers, and then basically if there's a match, a candidate [student teacher] wants it, we look up to see if there's somebody even available, and then it goes through [the department chair] and myself for placement.

The fit component mentioned by Mrs. Yellow is described as a match, but the importance of the connection and link to the cooperating teacher is noted as important in both descriptions.

Mrs. Yellow went on to explain this fit as being the beginning of an ongoing commitment between the hosting school and the student teacher, with the cooperating teacher being the link. This ongoing commitment was predicated, for Mrs. Yellow, on identifying commonalities between the cooperating teacher and the student teacher, even 
interviewing the student teacher to better identify if that person will be a fit with the potential cooperating teacher.

The principal did not play an active role in matching the cooperating teacher and student teacher or in the final selection of the cooperating teachers at Teal or Magenta High Schools. At Magenta High, the principal was mentioned by Mr. Red as simply providing an automatic approval once the assistant principal and department chair had given their endorsement. In contrast, at Gold High School, Mrs. Yellow had conversations with her principal to brainstorm the potential cooperating teacher list, depicting a more involved role than at the other two schools.

Importance of individual preferences and perspectives. Satisfaction and agreement of the cooperating teacher were very important to all of the participants. Comments focused on the willingness of the cooperating teacher to participate in the process, as well as comments about the fit and match previously discussed. The individual preferences of the cooperating teacher were also mentioned, such as the individual's flexibility and desire to socialize with the student teacher. Mr. Pink provided an example of socializing that involved the student teacher being invited to join the cooperating teacher and other colleagues "out for beers on a Friday." Additionally, the individual preferences of the student teacher were also a factor in the Choose CT activity. Mrs. Yellow even described the possibility that a more organized student teacher could serve as a role model for a disorganized yet effective cooperating teacher. Individual likes and dislikes were also a factor in the selection process.

Mr. Blue explained that the relationship, based on shared philosophies, allows for more genuine feedback from the cooperating teacher to the student teacher. When there 
is difficult information to be shared, the information can be better received if there is a pre-established relationship, in the view of Mr. Blue. He defended that the positive relationship prevents the negative feedback from being viewed as "antagonistic."

Overall, the process of selecting cooperating teachers was described by participants as collaborative, with a significant amount of attention being given to the preferences of the student teacher and cooperating teacher, with the voice of the cooperating teacher being most important in the placement process. The value of the cooperating teacher's voice, in turn, is a bit of a self-fulfilling prophesy in that an individual cooperating teacher who is seen by the department chair as a good match for multiple student teaching candidates is likely to be repeatedly selected as a cooperating teacher. The cooperating teachers were selected because of their ability to fit within this collaborative process, suggesting a teacher who was not collaborative would not be preferred as a cooperating teacher.

\section{Research Question \#2}

What professional qualities do administrators consider most important in the selection of high school core content area cooperating teachers?

Based on the feedback of the five participants, selection of cooperating teachers focused on three themes of professional qualities. The professional qualities are presented as traits that would be components in Domain 4 of Danielson's (2007) FfEt. Two of these qualities can be documented more formally: experience and professional development. The third theme is more difficult to document and to measure: attitudes and beliefs. 
Experience. The individual cooperating teacher's experience was a quality cited several times by all of the participants. The experience was described in different ways, with consideration given to experiences both in and out of the classroom. Within the classroom, experience teaching a variety of courses was desired by both department chair and assistant principal participants. Cooperating teachers who had taught a variety of courses, at both regular and honors levels, were desired. However, cooperating teachers who taught advanced placement courses were not as appealing to the participants.

When asked to select among the three potential cooperating teacher descriptions, all of the participants made mention of the teaching assignment of the cooperating teacher being a factor in whether or not that individual would be selected. Mr. Red directly stated that "a lot of decisions are made based on courses that teachers teach." Four of the five participants noted that Mrs. Y, the cooperating teacher whose schedule included advanced placement courses, would not be a candidate because of these advanced placement courses. These courses were seen as unlikely to be assigned to a first year teacher and, for this reason, a poor training ground for a student teacher. Mr. Red said it would not provide student teachers a "true reality of what teaching will be." Mrs. Yellow felt Mrs. Y, the teacher regularly assigned to teach advanced placement courses, may have been a good fit as a cooperating teacher if the student teacher had an interest in and had been prepared to teach an advanced placement course.

Another detail of experience that was referenced by all participants was the years of experience in overall teaching, with two participants directly citing tenured status as a requirement. Upon review of board of education policies at all three schools, none of them listed tenured status or any other specific qualities for cooperating teachers. The 
tenured status appears to have been an implied rather than documented requirement.

Though the board of education documents did not require tenured status of the cooperating teacher, the policies did require that the cooperating teachers must meet the qualifications of the "students' respective colleges or universities." Such qualifications, or the need to meet them, were not mentioned by any participants.

Beyond the status of tenure, which can be reached in 4 years of continued teaching within a district, there was a consistent pattern of the number of years that were desired for an ideal cooperating teacher. Department chairs and assistant principals, alike, hesitated to select a cooperating teacher who has a long history of teaching experience, concerned that these teachers would be stagnant and unwilling to learn from the student teacher. There was a mid-career window described by participants as an ideal time, the "sweet spot of her career," according to Mr. Pink, to serve as a cooperating teacher. Mr. Purple outlined his logic for why he, too, looks for cooperating teachers in this particular phase of their career:

I target specifically in years 5-10; it's the next step in terms of growth. Year 1, or a first year teacher, you would normally look at behavioral issues, or classroom management. Year 2, you start looking at their planning. Year 3, you now start to see their specific style as a teacher. Year 4, you look at the whole package. Years 5-10 you're looking at complete growth and how do they provide an impact, a positive impact to the department. One way to do that is by showing their expertise to a student teacher.

All of the participants found value in some, but not too much, teaching experience in a variety of courses to be desirable background for a potential cooperating teacher.

The experience of a cooperating teacher in extracurricular activities was also a factor considered in selection. Cooperating teachers who had coached a sport or served as an extracurricular activity sponsor were expressed as more desirable because of the 
connections they could provide for student teachers. These cooperating teachers were seen as having more in common with the student teachers, the personal perspective previously discussed, and also an envoy for the student teacher to secure some type of future extracurricular assignment.

Professional development. Participation in professional development was viewed as a positive trait in considering potential cooperating teachers. According to the participants representing the building and department levels, the professional development could have been provided in the form of additional college or university coursework. It also would have been in the format of professional workshops or reading. These growth opportunities were described by the participants as indicating an openness to continued growth that could occur with a student teacher, as well as a preparedness to have extended knowledge and skills to pass on to a student teacher.

Professional development, described as involvement in the building school improvement team, was cited by all five participants as one of the primary reasons for selecting Ms. Z as their first choice for cooperating teacher.

Attitudes and beliefs. Additional professional qualities beyond coursework and formal professional development were also noted consistently in the interviews. Certain attitudes and beliefs of potential cooperating teachers were also factors noted by the respondents. These traits were coded as professional qualities because of their direct reflection within the professional (school) environment. Participants desired flexibility as a characteristic that would provide for a more comfortable and supportive experience for the student teacher. With a flexible cooperating teacher, participants explained the student teacher would then have a model for the type of flexibility they would need to 
exhibit themselves as teachers.

Mr. Purple and others also identified the trait of "energy" as being desirable in cooperating teachers. This trait was highlighted as part of showing the type of enthusiasm for the profession that could be adopted by the student teacher. This enthusiasm was described by Mr. Blue as genuinely enjoying students. He explained that if he were coaching a student teacher, he "can teach you the content...can't teach you to like kids."

Beyond these affective professional qualities, all of the participants were strongly swayed by the quality of organization as a determining factor in selecting a cooperating teacher. Though none of the respondents described organization as an overt factor to be considered, all of the respondents selected Ms. Z as their top choice for cooperating teacher, ultimately citing her organizational skills as one of the top reasons for selecting her. This shows the appeal of organization as a trait in cooperating teachers.

Being reflective was another trait repeatedly identified as valuable in a cooperating teacher. Mr. Purple explained that "no matter what years of experience that they have, they're gonna continue to reevaluate and evolve as a teacher, with the students." The ability to honestly look at one's practice, identifying areas of strength and areas for improvement, was identified as a necessary trait to model for student teachers. This reflective nature was selected by three of the participants as being within their top 3 of the 11 traits of a cooperating teacher when asked to sort the discrete traits: Mr. Blue, Mr. Red, and Mrs. Yellow. Mrs. Yellow summarized this self-improvement practice was necessary, with cooperating teachers modeling "how to reflect and how to change their practice." None of the participants included reflection in their list of bottom three traits 
when sorting the 11 trait options of a cooperating teacher.

\section{Research Question \#3}

What instructional qualities do administrators consider most important in the selection of high school core content area cooperating teachers?

Considerably fewer responses were tied to instructional qualities than to professional qualities. The responses that did relate to this portion of the research consistently connected to the themes of curricular alignment and effective use of assessment.

Curricular alignment. Teaching the approved, aligned curriculum was identified as necessary for cooperating teachers to show student teachers effective practices. Mrs. Yellow identified a teamwork model as an effective means of working on aligned curriculum with a student teacher, citing her own cooperating teacher as having provided used this model of guidance. Alongside the curricular alignment was the importance of planning and preparation, recognized as a repeated stumbling block for student teachers. All but one of the participants cited the importance of student teachers becoming aware of exactly how much time and effort is necessary outside of the classroom to ensure the delivery of an effective lesson. Participants explained the value of the cooperating teachers in developing this awareness.

Use of assessment. Effective use of assessment data was mentioned by all but one of the participants as an essential trait for cooperating teachers through their interviews. When asked to sort the 11 possible qualities of a potential cooperating teacher, all of the participants cited the use of formative and summative assessment to guide instruction as one of the top three traits, with three participants citing it as the second most important and one participant each citing it as the first and third in rank. Mr. 
Red summarized how this trait is operationalized, noting the modeling of this skill allows a "student teacher to grow and understand how to respond to student needs and how to plan the next day."

The value of assessment was referenced by Mr. Blue and Mr. Pink, but not by the other three participants until it was first prompted through the Trait Sort segment of the interview. Once the trait (use of formative and summative assessment to guide instruction) was introduced to the participants, all of them included it within their top three traits, with Mr. Blue choosing it as the most important trait, and all of the participants sharing extended comments on the importance of this skill in a cooperating teacher.

\section{Research Question \#4}

In what ways, if any, do administrators' perception of a staff member within the department, building, or district influence the selection of that individual as a cooperating teacher?

There was no mention of any district perception factoring into the selection of an individual as a cooperating teacher, and building perception was reported to play a minimal, if any, role. Perception in the building was limited, as only Mrs. Yellow described an active role of any other building administrators, namely the principal, being involved in the selection of cooperating teachers. The department perception added to the likelihood of administrators selecting cooperating teachers who were viewed as role models, ready for growth, and prepared to contribute to the profession.

Role models. Teachers who were viewed departmentally as role models for other teachers were described as good choices to serve as cooperating teachers. Role models were those individuals who had themselves consistently evidenced "high quality instruction and assessment," according to Mr. Blue. He further describes this role 
modeling as being similar to a "teaching hospital" where the growth of the "novice" is the focus.

Growth opportunity. Four of the five participants described preparedness for growth as a trait making a teacher more likely to be selected as a cooperating teacher. Mr. Pink explained that this perception of growth readiness is not always how the role of a cooperating teacher has been viewed. According to his experience, previous cooperating teachers were selected as a reward, with the reward being an escape from teaching. A similar memory was shared by Mr. Red, who noted there are teachers who “just take it as an opportunity to have a break... and that's not what it should be." Mr. Blue disappointedly shared examples of schools whose practice it is to use a student teacher to cover for a tenured staff member whose skills are deficient. All participants felt the process that provided for a strong role being played by the department chair limits the likelihood of these issues, ensuring that the person who—as Mr. Red said——"knows his people best" establishes who will be a cooperating teacher.

Contributing to the profession. In addition to perceived growth readiness, there was a perception that those who were chosen as cooperating teachers were ready to give back to the profession by playing a role in the professional cycle. The role of cooperating teacher was spoken about with reverence by all of the participants. Even participants whose own personal student teaching experience provided little guidance or instructional support defended their cooperating teachers. Mrs. Yellow initially characterized her student teaching experience as "interesting," lamenting she was paired with a cooperating teacher who was just one year from retirement. However, she quickly contrasted that by saying it was "a great experience... having a veteran teacher but then having a younger 
tenured teacher on the other side of the hall I was able to collaborate with." While the majority of her guidance came from this other unofficial cooperating teacher, Mrs. Yellow was proud to say her cooperating teacher "let me fail and that was good."

Mr. Pink shared an equally conflicted description of his own cooperating teacher. He summarized his introduction to his would-be mentor, recalling that his cooperating teacher introduced himself and immediately followed with a directive of "Hey, whatever you want to do that's totally fine!" He went on to say, "He got to play hearts a lot with his buddies in the faculty lounge." Despite this loosely guided experience, Mr. Pink heralded his cooperating teacher, saying, "Good guy_did I learn anything from him? No." The respect offered the role of cooperating teacher permeated all of the interviews, whether discussing one's own cooperating teacher or selecting potential cooperating teachers. The role of cooperating teacher was viewed by all as part of the educational cycle of giving back to the profession as a whole by overseeing the work of a student teacher. These departmental perceptions were strong, while building and district perceptions were less so.

\section{Research Question \#5}

What evidence do high school administrators use in selecting and reviewing the effectiveness of cooperating teachers? How does this evidence align with the Danielson (2007) Framework for Effective Teaching?

Throughout the interview probe responses and activities, several participants noted consideration of a teacher's evaluation rating in selecting cooperating teachers; however, they shared no formal evidence at all is used in evaluating the effectiveness of cooperating teachers while they are or after they serve in this role. Mr. Purple indicated his process is "informal," focusing on "conversation with the cooperating teachers." 
Non-verbal and verbal responses to this interview probe were particularly interesting in that several of the participants indicated such an evaluation would be appropriate and they were not sure why a tool for this purpose was not already in place. Mr. Blue and Mr. Purple both took noticeable pauses prior to responding to this question, initially surprised by the prospect of evaluating cooperating teachers specifically in the role of cooperating teacher. Mr. Red responded directly and with no opening for further discussion, "We don't." Mr. Pink, after expressing shock of his own, offered suggestions about the value of such a tool, while still seeming to be incredulous of the concept: "You know what? We, uh, we've never done that."

Evaluation ratings. The actual formal evaluation ratings of cooperating teachers from their teaching evaluations were referenced by some participants when reviewing the description of potential cooperating teacher Mr. X. The evaluation ratings of potential cooperating teachers were considered valuable. Evaluation ratings of Mrs. Y and Ms. Z were not included in the descriptions. While participants indicated a desire to have the evaluation ratings of these other potential cooperating teachers, all five participants still chose Ms. Z as a cooperating teacher over Mr. X or Mrs. Y, even without this piece of evidence being provided.

No evidence as evidence. Though limited concrete evidence was used in selecting cooperating teachers and even less evidence in evaluating their effectiveness, that lack of evidence is evidence in itself. Though cooperating teachers are spoken of as valued members of the student teaching experience, and the experience of student teaching is critical to the future success of the student teacher and ultimate achievement of pupils, the work of these individuals was largely unmonitored. 


\section{Comparison of the Case Study Districts}

The comments from participants at the three participating high schools were not significantly different from one another. The Choose a CT activity (Appendix D) selections of cooperating teachers were not consistent among the participants from individual schools, as shown in Table 3. If a participant did not feel a particular cooperating teacher, or more than one cooperating teacher, was a viable candidate for this role, then those individuals are not listed in the chart for that participant; they are noted as "no choice given."

Table 3

Choose a CT Activity Response

\begin{tabular}{|c|c|c|c|}
\hline Participant & $1^{\text {st }}$ choice for $\mathrm{CT}$ & $2^{\text {nd }}$ Choice for CT & $3^{\text {rd }}$ Choice for CT \\
\hline Mr. Blue & Ms. Z & Mrs. Y & Mr. X \\
\hline Mr. Purple & Ms. Z & Mr. X & Mrs. Y \\
\hline Mr. Red & Ms. Z & Mrs. Y & Mr. X \\
\hline Mr. Pink & Ms. Z & no $2^{\text {nd }}$ choice given & no $3^{\text {rd }}$ choice given \\
\hline Mrs. Yellow & Ms. Z & Mr. X & Mrs. Y \\
\hline
\end{tabular}

With no department chair participant from Gold High, no comparison from the department to building level was possible for that school. The information shared by the assistant principal and department chairs from Teal and Magenta High, separately, was also not consistent, suggesting there is no formal or perceived priority or philosophy regarding the selection of cooperating teachers at those individual schools. Given these inconsistencies, thorough case studies of the schools were not possible. Further, the traits identified as most and least important during the Trait Sort (Appendix E) were not 
consistent among participants from the individual schools, as shown in Tables 4 and 5.

Table 4

Trait Sort Activity Responses-Top Ranking Traits

\begin{tabular}{llll}
\hline Participant & \multicolumn{1}{c}{ Rank \#1 Trait } & \multicolumn{1}{c}{ Rank \#2 Trait } & \multicolumn{1}{c}{ Rank \#3 Trait } \\
\hline Mr. Blue & $\begin{array}{l}\text { Use of formative and } \\
\text { summative } \\
\text { assessment to guide } \\
\text { instruction }\end{array}$ & $\begin{array}{l}\text { Reflection on teaching } \\
\text { practices }\end{array}$ & $\begin{array}{l}\text { Engagement of } \\
\text { students in learning }\end{array}$ \\
Mr. Purple & $\begin{array}{l}\text { Knowledge of } \\
\text { students' skills, } \\
\text { knowledge, and } \\
\text { development }\end{array}$ & $\begin{array}{l}\text { Knowledge of } \\
\text { content-related } \\
\text { pedagogy }\end{array}$ & $\begin{array}{l}\text { Use of formative and } \\
\text { summative } \\
\text { assessment to guide } \\
\text { instruction }\end{array}$ \\
Mr. Red & $\begin{array}{l}\text { Reflection on } \\
\text { teaching practices }\end{array}$ & $\begin{array}{l}\text { Use of formative and } \\
\text { summative assessment } \\
\text { to guide instruction }\end{array}$ & $\begin{array}{l}\text { Knowledge of } \\
\text { students' skills, } \\
\text { knowledge, and } \\
\text { development }\end{array}$ \\
Mr. Pink & $\begin{array}{l}\text { Engagement of } \\
\text { students in learning }\end{array}$ & $\begin{array}{l}\text { Use of formative and } \\
\text { summative assessment } \\
\text { to guide instruction }\end{array}$ & $\begin{array}{l}\text { Knowledge of } \\
\text { content-related } \\
\text { pedagogy }\end{array}$ \\
& $\begin{array}{l}\text { Reflection on } \\
\text { teaching practices }\end{array}$ & $\begin{array}{l}\text { Use of formative and } \\
\text { summative assessment } \\
\text { to guide instruction }\end{array}$ & $\begin{array}{l}\text { Communication with } \\
\text { students }\end{array}$ \\
\hline Mrs. Yellow & & &
\end{tabular}

The prioritization of particular traits was not consistent within an individual school. This lack of evidence is evidence in itself, reflecting an inconsistency in the dominance of particular traits as priority in selecting cooperating teachers. The culture within each individual school did not dictate the prioritization of any particular traits. There was consistency of traits across schools, particularly with the lowest ranking traits, highlights the overall inconsistency in the espoused traits and the applied traits. For 
example, consistent selection of Ms. Z based on professional growth contradicts the selection of that trait as among the lowest ranking traits for four of the five participants.

Table 5

Trait Sort Activity Responses-Lowest Ranking Traits

\begin{tabular}{llll}
\hline Participant & Listed alphabetically, as participants did not rank in any specific order \\
\hline Mr. Blue & Knowledge of content & $\begin{array}{l}\text { M Lanagement of } \\
\text { classroom materials }\end{array}$ & $\begin{array}{l}\text { Participation in } \\
\text { professional growth } \\
\text { and school } \\
\text { improvement }\end{array}$ \\
Mr. Purple & $\begin{array}{l}\text { Communication and } \\
\text { partnership with } \\
\text { families }\end{array}$ & $\begin{array}{l}\text { Management of } \\
\text { classroom materials }\end{array}$ & $\begin{array}{l}\text { Participation in } \\
\text { professional growth } \\
\text { and school } \\
\text { improvement }\end{array}$ \\
Mr. Red & Knowledge of content & $\begin{array}{l}\text { Management of } \\
\text { classroom materials }\end{array}$ & $\begin{array}{l}\text { Management of } \\
\text { student behavior }\end{array}$ \\
Mr. Pink & Knowledge of content & $\begin{array}{l}\text { Management of } \\
\text { student behavior }\end{array}$ & $\begin{array}{l}\text { Participation in } \\
\text { professional growth } \\
\text { and school }\end{array}$ \\
& Knowledge of content & $\begin{array}{l}\text { Management of } \\
\text { classroom materials }\end{array}$ & $\begin{array}{l}\text { Participation in } \\
\text { professional growth } \\
\text { and school } \\
\text { improvement }\end{array}$ \\
& & &
\end{tabular}

While there was not consistency in the ranking of the traits, there were more similarities within a given school with regard to the lower ranking traits than with the higher ranking traits. For example, at Teal High, both participating administrators ranked management of classroom materials and participation in professional growth and school improvement within their lowest three traits; however, they did not have parallel 
selections within their highest ranking traits. Similarly, the participating administrators from Magenta High both ranked knowledge of content and management of student behavior within their lowest ranking traits, but they did not agree on the third within this group: one selected management of classroom materials, and one selected participation in professional growth and school improvement.

\section{Through the Lens of Danielson's Framework}

The data from the interview probes, the document analysis, the Choose a CT activity, and the Trait Sort activity have been reviewed through Charlotte Danielson's (2007) Framework for Effective Teaching, providing a usable tool for discussing the various dominant traits identified as important to the participating administrators, traits either directly stated as important or traits that were implied as important through the activities and probe responses.

The four domains of Danielson's (2007) FfET are separated according to the preparation for the lesson, Domain 1; the actual climate of and instruction within the learning environment, Domains 2 and 3; and the teacher's professional practices and traits, Domain 4. The major findings from the study are presented according to these domains.

\section{Domain 1: Planning and Preparation}

Responses from the participants throughout the interview included a strong commitment to helping student teachers learn to lesson plan. Evidence centered on the significant amount of time teachers commit to lesson planning and the difficulty of conveying this time commitment to student teachers. Participants shared examples of past student teachers who had difficulty understanding the need for this time commitment 
and, ultimately, being dismissed from their student teaching placement. The significant amount of time modeled, however, did not translate to the selection of $\mathrm{X}, \mathrm{Y}$, or $\mathrm{Z}$ as a cooperating teacher during the Choose a CT activity. (See Appendix D.) No evidence was provided about the lesson planning practices of any of the sample cooperating teachers $(\mathrm{X}, \mathrm{Y}$, or $\mathrm{Z})$ described in this activity, and when given the opportunity to identify additional information that would be useful in making their selection, none of the participating administrators requested information about the planning practices of these potential cooperating teachers. While the development of effective planning practices was repeatedly mentioned as important though difficult for student teachers to learn, knowledge of the cooperating teachers' practices in this area were not depicted by the participants as necessary in selecting cooperating teachers.

Though the lesson planning component was implied as important, knowledge of content was repeatedly a lower priority. Additionally, participants conveyed a clear understanding of the distinction between knowledge of content and knowledge of content-related pedagogy, expressing the pedagogical content as being more important for the cooperating teacher. This priority was consistent with participants' choice not to prioritize Mrs. Y, who was a veteran staff member in the Choose a CT activity, as a cooperating teacher. While her content knowledge was exemplary, teaching advanced placement courses, this was not seen as a persuasive reason to choose her over Ms. Z, the mid-career teacher in the Choose a CT activity.

During the Trait Sort, no components from this domain were ranked consistently within the top three dominant traits selected by the participants; however, two participants did rank knowledge of content-related pedagogy as part of their top three 
traits. Four of the five participants ranked knowledge of content, which is part of this domain, within the least important of the presented traits during the Trait Sort.

\section{Domain 2: The Classroom Environment}

The participants expressed sensitivity to what they characterized as a typical challenge for student teachers: classroom management. Responses from the participants focused on the importance of cooperating teachers setting the tone for student teachers to assume control of the classroom. While this was described as an important role for the cooperating teacher to play, the Trait Sort communicated a different priority. Four of the five participants ranked management of classroom materials as one of the least important traits. Three of the five participants ranked management of student behavior as one of the least important traits, though they did justify this by explaining a solid lesson diminishes students' propensity for misbehavior. Overall, participants considered the qualities in this domain less important than those in the other domains.

When asked to rank the three most important qualities from the 11 qualities of potential cooperating teachers, all of the participants ranked one or more trait from this domain within the least important grouping. When asked to select a cooperating teacher from the three descriptions provided, Ms. Z was repeatedly selected, specifically for her organizational skills, skills that are part of Domain 2. Still, none of the participants ranked any components from this domain within their top three sort of most important traits.

\section{Domain 3: Instruction}

Responses related to this domain repeatedly highlighted the usefulness of the cooperating teacher having the ability to model for and train the student teacher to use 
formative and summative assessment to guide instruction. This was the only unanimously chosen trait among all of the participants' top three most important traits ranked during the Trait Sort. Three of the participants ranked the use of formative and summative assessment to guide instruction as second in their top three traits; the other two participants ranked this trait first and third. Interestingly, Mrs. Yellow and both participants from Magenta High raked this trait second in their Trait Sort, while the two participants from Teal High ranked this trait first and third in their sort. Further highlighting participants' value of this trait, participants also commented on the merit of assessment used in instruction during the interview probe portion of the interviews. Mr. Blue captured the desired practice in saying the effective teacher will have objectives broken down into language students can understand and then "assess as we go along to make sure that we know the kids are learning it."

\section{Domain 4: Professional Responsibilities}

Two components from this domain were chosen by participants during the Trait Sort of most and least important qualities from the strips provided. This domain, uniquely, was noted for a component that was among the three most important for three of the five participants and also for a component that was among the three least important for four of the five participants. Four participants identified participation in professional growth and school improvement as being among the lower priorities for cooperating teachers. This contradicted the praise for Ms. Z, the popularly chosen teacher in the Choose a CT activity, and her ability to better prepare student teachers for the profession because of her participation in the building school improvement process. Three participants identified reflection on teaching practices among the top traits for a 
cooperating teacher. There was no evidence about the reflection practices of the prospective teachers provided, but this did not prevent all of the participants from enthusiastically selecting Ms. Z as their first choice for cooperating teacher during the Choose a CT activity.

\section{Summary}

In interview conversations ranging from 30 minutes to more than double that time, the participants completed two activity components following the primary interview probes: (a) Choose a CT—-selecting cooperating teacher candidates from descriptions of three potential cooperating teachers, and (b) Trait Sort-identifying the top three most important and least important traits for a cooperating teacher, choosing from a collection of 11 elements selected from Danielson's (2007) FfET. Analyzing the evidence from the interview prompts and the activity components, several notable patterns emerged. All of the participants identified Ms. $\mathrm{Z}$ as their first choice to serve as a cooperating teacher, naming her professional development and organization as the justification for their selection.

There were no clear patterns for a second choice beyond the selection of Ms. Z. Two participants, Mr. Blue and Mrs. Yellow, selected Mr. X as their second choice, indicating a likely ability to connect with the student teacher, because of his young age, and his coaching experience, as persuading factors. Perceptions of Mrs. Y as a cooperating teacher were mixed. Two participants, Mr. Purple and Mr. Red, selected Mrs. Y as their second choice, while Mrs. Y and Mr. X were not seen as options by Mr. Pink. He said the student teacher "might get dumber" from working with Mrs. Y and that Mr. X "might get more out of the process than the student teacher"; neither of these 
teacher descriptions was an option to serve as a cooperating teacher, according to Mr. Pink.

When reviewing the dominant traits identified as most important from the 11 elements provided, participants most often selected the use of formative and summative assessment to guide instruction and reflection on teaching practices. All five participants noted the assessment trait in their top three traits; three of the five participants noted reflection within the top three traits.

While the participants all cited the effective use of assessment and reflection as important traits, these traits were not consistently discussed prior to being introduced by the researcher during the activity portions of the interviews. Only Mr. Pink and Mrs. Yellow discussed reflection prior to the activities, with Mrs. Yellow only mentioning it casually as a benefit provided to cooperating teachers after having a student teacher. Mr. Pink, in contrast to Mrs. Yellow and in stark contrast to the other participants, repeatedly discussed the merit of reflection for both cooperating teachers and student teachers.

Discussion of the effective use of assessment was only introduced by Mr. Pink and Mr. Blue prior to the trait prioritizing activity. Though participants eagerly selected reflection and assessment characteristics as top qualities for cooperating teachers, these were not mentioned even when participants were directly asked if there were additional pieces of information or details they would have liked to have known about the three sample cooperating teacher descriptions, as additional information to guide their decision. 
CHAPTER V

CONCLUSIONS, IMPLICATIONS, AND RECOMMENDATIONS

\section{Introduction}

This chapter includes six major parts. To begin, the overview of the study reviews the purpose and participants, as well as the research study design and methodology. The second section summarizes the results; conclusions drawn from these results comprise the third section of this chapter. The fourth section of the chapter reviews the implications for practice and strategies for implementation based on the analysis of the study results. The fifth section outlines the limitations discovered through the course of the study. Finally, the sixth section makes recommendations for future studies.

\section{Overview of the Study}

With the role of the teacher being the most significant factor in pupil achievement (Wright, Horn, \& Sanders, 1997), the training provided in student teaching is critical to the success of future generations of pupils. Student teaching is the true application of an educator's preparation through university coursework, with the transition from student to teacher taking place during the student teaching experience. The coordination of the student teacher's placement - particularly the selection of the cooperating teacher-is critical in this training and transition process. This study presented an analysis of high school administrators' perspectives of the dominant traits they considered relevant in the selection of cooperating teachers. 
The purpose of this study was to investigate the dominant traits high school administrators considered most important in selecting cooperating teachers, with specific focus on how these traits aligned with Danielson's Framework for Effective Teaching. The study analyzed the participants' feedback to identify factors administrators considered either explicitly or implicitly in selecting individuals to serve as cooperating teachers.

The participants in the study were all involved in the student teaching placement and cooperating teacher selection processes within their school. The high schools represented were identified, through publicly available data, as schools committed to growth and improvement, centered on improved pupil learning and collaboration. The group was narrowed to eight schools using purposive sampling, with all of the high schools being part of large unit districts as defined by the Illinois State Board of Education through the Illinois Interactive Report Card. That initial group was then further narrowed to three schools using random sampling. No schools from my own district were used. Participants included four males and one female, though the gender mix was not intentional nor explored as a factor in this study. Mr. Blue and Mr. Purple were administrators, assistant principal and science department chair, respectively, at Teal High School. Magenta High School was represented by assistant principal, Mr. Red, and the department chair for English, Mr. Pink. The final participant was Mrs. Yellow, assistant principal at Gold High School; there was no corresponding department chair from this school due to difficulty in securing additional participants.

The study began with a general interest in the internship step for every career educator: student teaching. An interest in the factors driving the selection of cooperating 
teachers evolved from earlier pilot studies on this topic. This final study investigated the factors directly stated and implied in discussion and activity components regarding the selection of cooperating teachers. The qualitative design allowed for rich description of the process for selecting cooperating teachers, as seen through the eyes of the various educators involved. The data gathered in this study were analyzed through Danielson's (2007) Framework for Effective Teaching, which served as the conceptual framework for the study.

\section{Summary of Findings}

\section{Research Question \#1}

How do administrators describe the process for selecting cooperating teachers in core content areas at the high school level?

Administrators described the process for selecting cooperating teachers as collaborative and rich, involving multiple stages of conversations, as well as interviewing of student teachers. The process is viewed as including multiple phases, with specific roles and responsibilities for the building administrators, the cooperating teacher, the student teacher, and the district human resources department. The personal preferences and interests of the cooperating teacher and student teacher were communicated as important in the selection of the cooperating teacher. Efforts were consistently made to match the personalities, philosophies, and interests of the student teacher and the cooperating teacher.

\section{Research Question \#2}

What professional qualities do administrators consider most important in the selection of high school core content area cooperating teachers? 
A commitment to professional development was seen as a valuable trait of cooperating teachers. Participants preferred cooperating teachers who were continuous learners involved in documented school improvement efforts. Further, a particular window of experience, from 5 to 15 years of teaching, was seen as the ideal time for someone to serve as a cooperating teacher. Preference was also given to teachers who were assigned to teach a variety of regular and honors, but not advanced placement, courses. A very strong preference was given to cooperating teachers who were reflective by nature and enthusiastic about teaching.

\section{Research Question \#3}

What instructional qualities do administrators consider most important in the selection of high school core content area cooperating teachers?

The use of formative and summative assessment to guide instruction was cited as the most important instructional quality administrators sought in cooperating teachers. Administrators preferred individuals who had experience with designing lessons in response to assessment data. Also valued was maintenance of the approved curriculum.

\section{Research Question \#4}

In what ways, if any, do administrators' perception of a staff member within the department, building, or district influence the selection of that individual as a cooperating teacher?

There was no evidence that any type of perception within the district contributed to a teacher being chosen as a cooperating teacher. Aside from the human resource department's role in student teacher paperwork, there was no meaningful connection between any parts of the student teaching or cooperating teacher process and the district. Aside from the assistant principal, there was no significant role played by any other 
building administrators. The assistant principal deferred to the department chair as being more intimately connected to potential cooperating teachers. There was little evidence of a building perception contributing to the selection of a teacher as a cooperating teacher.

At the department level, teachers perceived to be role models who showed a preparedness to grow were preferred as cooperating teachers. A perception of respect was strong for individuals serving as cooperating teachers, as they were seen as contributing to the future of the profession.

\section{Research Question \#5}

What evidence do high school administrators use in selecting and reviewing the effectiveness of cooperating teachers?

A strong teacher evaluation rating was cited as valuable, but little evidence during the interviews confirmed this. The lack of evidence, particularly in evaluating the effectiveness of cooperating teachers, was noted as evidence in itself. Without any tools for gathering more specific evidence of a cooperating teacher's effectiveness, there are questions as to how effective some cooperating teachers really are. Participants did respectfully refer to Danielson's FfEt; however, they did not cite particular components or elements as being important to them in selecting someone to serve as a cooperating teacher.

\section{Conclusions}

The participants' responses were consistent with the research literature in that there are multiple people involved, yet responses added to the research in detailing the roles and responsibilities of those involved in selecting cooperating teachers. The participants also echoed the concern in the research about the limited communication 
between universities and cooperating teachers. When asked about evaluation of the effectiveness of the cooperating teachers as cooperating teachers, rather than only as classroom teachers, the participants recognized that this area might be an area for review. All five of the study participants were complimentary of the student teaching placement and cooperating teacher selection processes as a whole, expressing the importance of student teaching in developing a novice teacher. Special recognition was given to the role of the cooperating teacher and the special relationship that develops between a student teacher and his or her cooperating teacher.

\section{Implications and Strategies}

The findings of this study provide important implications for both district and building administrators, as well as university partners. In determining the implications of the results of this study, there are two primary areas for consideration: qualifications for cooperating teachers and evaluation.

\section{Qualifications for Cooperating Teachers}

Research (Borko \& Mayfield, 1995; Babkie, 1998) notes the role a cooperating teacher can play as a role model for student teachers, but the specific qualities that cooperating teachers would be expected to model are not outlined specifically for those selecting the cooperating teachers. For example, while all study participants recognized the important role of the cooperating teacher in the student teacher's experience, there were inconsistencies in the discrete identification of and the application evidence of these traits of cooperating teachers. When selecting actual cooperating teachers, as done in Activity \#1 (Choose a CT), the traits selected as most persuasive in Activity \#2 (Trait Sort) were not sought or referenced. Instead, participants repeatedly cited organization 
and work beyond the classroom — in the areas of school improvement — as leading them to select a particular cooperating teacher from the three descriptions provided. Yet, when selecting discrete traits for a cooperating teacher from a list of traits, as done in Activity \#2 (Trait Sort), administrators identified traits Marzano's (2003) meta analysis cited as among those most significant in improving pupil learning.

When looking directly at particular traits, administrators identified the traits cited as most critical to improving pupil learning; the gap occurred in transferring that knowledge to the application moment within the cooperating teacher selection activity, Activity \#1. This is especially concerning given that responsibility for selecting cooperating teachers falls entirely upon the district, with the universities, based on participant feedback, simply assuming qualified teachers are being selected to fulfill this critical role. While participants lauded the building-level decision making, this independence may need more guidance.

The implication for educational leaders is that a clear list of qualifications for cooperating teachers needs to be developed. This list of qualifications should be based on district expectations, but it should be developed in cooperation with partnering universities. The qualifications should, as discussed, focus on instructional rather than only professional competencies. Additionally, a qualifications list will not be sufficient without a rubric or assessment tool to ensure the qualifications are present and exhibited at a high level. The adoption of Danielson's FfET as a widespread teacher evaluation tool is a step in the right direction. Still, administrators need further guidance and support in transferring the evidence from those evaluations into their practices for selecting cooperating teachers. 


\section{Evaluations}

All study participants reflected that evaluation of student teachers is based solely on university criteria. The district's input is only in completion of the evaluation form, not in the determination of what is being evaluated. With a teacher evaluation moving toward the inclusion of pupil achievement (Danielson, 2002), student teacher evaluation needs also to include this component. While all teachers throughout the state of Illinois are required to be evaluated and categorized on a regular basis, universities and districts loosely evaluate student teachers, providing no training for cooperating teachers, no expectations of how they need to support student teachers in their development. Observing student teachers with consistent and rigorous tools would provide realistic indicators of a potential candidate's likely future performance. These indications can show the role a candidate could play in the future of the school and also particular areas for improvement, as a means of improving student achievement.

The use of enhanced evaluation tools is also important in evaluating the effectiveness of cooperating teachers. Cooperating teachers need to have evidence of their ability to teach pupils but also their ability to transfer those skills to the student teachers.

The implication for school leaders is to collaborate with universities to develop a cooperating teacher evaluation tool, as well as a modified student teacher evaluation tool, that will focus on measurable improved pupil achievement. An additional implication is for school leaders to observe student teachers, or at the very least to partner closely with the cooperating teachers who observe them, to appropriately use the district evaluation tools to monitor and improve student achievement and to provide opportunities for the 
cooperating teacher to maximize the growth available from serving as a cooperating teacher.

\section{Limitations}

The study was significantly limited by the small number of participants and the narrowing of the participant pool. While this narrowing was necessary for pragmatic reasons, it also narrows the generalizability of the resulting data and conclusions. One limitation that had not been anticipated prior to the onset of the study was the difficulty of securing individuals to participate in the study. Several individuals simply did not respond to the invitation to participate, resulting in five rather than six participants.

\section{Recommendations for Future Research}

To develop a signature pedagogy that is more beneficial to students in classrooms, a stronger focus must be placed on the community component of learning for teachers both in the student teaching and professional practice phases. The capacity for good teaching hinges on the knowledge of content, the ability to coherently and productively share that content, and the desire to do so. That desire stems from the culture within a school and in education as a field. Teaching is part of a "generative dance," according to Lampert (2012). The culture of the organization is changed, which changes the individuals in the organization, which changes the culture of the organization.

Extending the learning beyond the student teaching phase provides an opportunity to develop an additional signature pedagogy, that of the during-practice learning of the cooperating teacher. This community of learning extends the signature pedagogy of teacher training across the line from school administrator to cooperating teacher, with the signature pedagogy of educational leadership resting on the marriage of school 
improvement planning and professional development (Sappington, Baker, Gardner, \& Pacha, 2010). More closely aligning the signature pedagogy of cooperating teachers with that of educational leaders would provide a new link within the educational community. This reciprocal relationship between individual and organization supports Shulman's recommendation that teachers create their own accountability by taking responsibility for their students' success (Shulman, "No Drive-by Teachers"). If teachers continue to see their work as part of an isolated performance, then they cannot meet the demands of $21^{\text {st }}$ century learners.

Learners of the future need to be prepared to apply knowledge more effectively than any learners of the past. The instruction of teachers needs to change to better prepare teachers to facilitate thinking instead of memorizing and summarizing information. Teachers must be prepared to collaborate with one another in order to foster the type of intentional inquiry and problem-solving mindset necessary to be effective. As researched by Darling-Hammond (2010), the highest-achieving nations have "overhauled teacher education to ensure stronger programs across the enterprise and to ensure that able candidates can afford to become well prepared as they enter the profession" (p. 198).

Teacher education and professional development must be centered in practice in an authentic way. Ball and Forzani (2009) argue teaching is "unnatural" and "intricate" (pp. 498, 500) work that requires individuals to be taught and to practice their craft in ways unique to the profession. "Teaching requires an unnatural attention to the 'what' of that which they are helping others learn" (Ball \& Forzani, 2009). Teachers are consistently asking unusual types of questions to which they already know the answers and are listening for not just the right answer but the path of misunderstanding that may 
be intimated by the wrong answers. To help improve the profession of teaching, Ball and Forzani (2009) insist teachers must abandon archaic notions that creativity and style are the cornerstone of their practice.

This study provides a clear picture of the factors perceived relevant by these participants, but several other related areas could be examined with further research. One recommendation for future research is to expand the study to include additional participants representing other roles in the student teacher placement process, specifically the student teacher and the university supervisor. An additional recommendation for expanding the respondent pool would be to have fewer criteria in narrowing the initial sample. Alternatively, the study could also be repeated with different criteria used to narrow the sample, comparing and contrasting the results from that study with the results from this study, to identify whether the factors perceived relevant in the selection of cooperating teachers are similar across school districts or geographic regions, moving toward the development of grounded theory (Merriam, 2009).

A second direction for this research would be further enhancement of the activity components. While several participants joked about being challenged by the activity portions, all of the participants were eager and animated during this portion of the interviews, suggesting a comfort level that likely provided for less guarded and more genuine responses.

To use this research as the launch of an entirely different yet related study, a study could be designed wherein a cooperating teacher evaluation tool could be developed and piloted, with the results analyzed in two significant ways: (a) consistency, or lack thereof, among the feedback from the student teacher, cooperating teacher, building 
administrator, and university supervisor, and (b) patterns of areas for support to be provided for future cooperating teachers to provide enhanced guidance and modeling for student teachers. Such a tool, ideally, could also be used formatively to help individual cooperating teachers grow in their own practice and in their modeling for student teachers, even during the time of the student teaching placement. 


\section{REFERENCES}

Angell, A. (1998). Learning to teach social studies: A case study of belief restructuring. Theory and Research in Social Education, 26, 509-529.

Babkie, A. (1998). Work successfully with a student teacher. Intervention in School and Clinic, 34(2), 115-117.

Ball, D. L., \& Forzani, F. M. (2007). Wallace foundation distinguished lecture-What makes education research "educational"? [Electronic version]. Educational Researcher, 36(9), 529-540.

Bobbitt, F. (1913). The Twelfth Yearbook of the National Society for the Study of Education: Part I-The Supervision of City Schools. Chicago, IL: The University of Chicago Press.

Bolin, F. S. (1988). Helping student teachers think about teaching: Another look at Lou. Journal of Teacher Education, 41(1), 10-19.

Bolman, L. G. \& Deal, T. E. (2008). Reframing organizations: Artistry, choice, and leadership. San Francisco: Jossey-Bass.

Borko, H., \& Mayfield, V. (1995). The roles of the cooperating teacher and university supervisor in learning to teach. Teaching and Teacher Education, 11, 501-518.

Boyd, D. J., Grossman, P. L., Lankford, H., Loeb, S., \& Wyckoff, J. (2009). Teacher preparation and student achievement. Education Evaluation and Policy Analysis, $31,416-440$.

Boyd, V., \& McGree, K. (1995). Leading change from the classroom: Teachers as leaders. Issues about Change, 4 (4). Austin, TX: Southwest Educational Development Laboratory.

Bozella, D. L. T. (2008). An examination of the practices and perceptions of student teaching coordinators for matching student teachers with clinical placement sites in Pennsylvania. Available from ProQuest Dissertations and Theses database. (UMI No. 3336001).

Britzman, D. P. (1986). Cultural myths in the making of a teacher: Biography and social structure in teacher education. Harvard Educational Review, 56(4), 442-456. 
Brooks, J. G. (1990). Teachers and students: Constructivists forging new connections. Educational Leadership, 90(47), 68-71.

Brooks, J. G., \& Brooks, M. G. (1999). In search of understanding: The case for constructivist classrooms. Alexandria, VA: ASCD.

Brouwer, N., \& Korthagen, F. (2005). Can teacher education make a difference? American Educational Research Journal, 42(1), 153-224.

Bryk, A., \& Schneider, B. (2002). Trust in schools: A core resource for improvement. New York: American Sociological Association.

Butterweck, J. S. (1951). Student teaching-When, where, and how? Journal of Teacher Education, 2, 129-142.

Callahan, R. E. (1962). Education and the cult of efficiency. Chicago: The University of Chicago Press.

Campbell, L. P., \& Williamson, J. A. (1983). Supervising the student teacher: What is really involved? NASSP Bulletin, 67, 77-79.

Clift, R., \& Brady, P. (2005). In M. Cochran-Smith \& K. M. Zeichner (Eds.), Studying teacher education, Research on methods courses and field experiences (pp. 309424). Mahwah, NJ: Lawrence Erlbaum.

Cochran-Smith, M. (1991). Reinventing student teaching. Journal of Teacher Education, 42, 104-118.

Coleman, J. S., Campbell, E. Q., Hobson, C. J., McPartland, J., Mood, A. M., Weinfield, F. D., \& York, R. L. (1966). Equality of educational opportunity. Washington, DC: U.S. Department of Health, Education, and Welfare.

Collier, S. T. (1999). Characteristics of reflective thought during the student teaching experience. Journal of Teacher Education, 50(3), 173-181.

Conderman, G., \& Pedersen, T. (2006). Supporting student teachers. NASSP Bulletin, 90(4), 335-342.

Conklin, H. G., (2009). Purposes, practices, and sites: A comparative study of two pathways into middle school teaching. American Educational Research Journal, 46(2), 463-500.

Consortium for Educational Change. (2013). Locations-Member districts 2012-13.

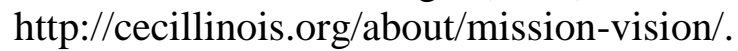

Corcoran, T., \& Goertz, M. (1995). Instructional capacity and high performance schools. Educational Researcher, 24(9), 27-31. 
Cornbleth, C., \& Ellsworth, J. (1994). Teachers in teacher education: Clinical faculty roles and relationships. American Educational Research Journal, 31(1), 49-70.

Covey, S. (1990). Principle-centered leadership. New York, NY: Simon \& Schuster.

Cuban, L. (1984). How teachers taught: Constancy and change in American classrooms. New York, NY: Longman.

Danielson, C. (1996). Enhancing professional practice: A framework for teaching $\left(1^{\text {st }}\right.$ ed.). Alexandria, VA: ASCD.

Danielson, C. (2000). Teacher evaluation to enhance professional practice. Alexandria, VA: ASCD.

Danielson, C. (2002). Enhancing student achievement: A framework for school improvement. Alexandria, VA: ASCD.

Danielson, C. (2007). Enhancing professional practice: A framework for teaching $\left(^{\text {nd }}\right.$ ed.). Alexandria, VA: ASCD.

Danielson, C. (2008). The handbook for enhancing professional practice: Using the framework for effective teaching in your school. Alexandria, VA: ASCD.

Danielson, C. (2009). Implementing the framework for teaching in enhancing professional practice. Alexandria, VA: ASCD.

Darling-Hammond, L. (2006). Constructing $21^{\text {st }}$ century teacher education. Journal of Teacher Education, 57(10), 1-15.

Darling-Hammond, L. (2010). Teacher education and the American future. Journal of Teacher Education, 61(1-2), 35-47.

Darling-Hammond, L. (2010). The flat world and education: How America's commitment to equity will determine our future. New York, NY: Teachers College Press.

Darling-Hammond, L., Banks, J., Zumwalt, K., Gomez, L., Sherin, M. G., Griesdorn, J. M., \& Finn, L. (2005). Educational goals and purposes: Developing a curricular vision for teaching. In L. Darling-Hammond \& J. Bransford (Eds.). Preparing teachers for a changing world: What teachers should learn and be able to do (pp. 169-200). San Francisco, CA: Jossey-Bass.

Dean, C. B., Hubbell, E. R., Pitler, H., \& Stone, B. (2012). Classroom instruction that works: Research-based strategies for increasing student achievement $\left(2^{\text {nd }} \mathrm{ed}\right.$.). Alexandria, VA: ASCD.

Del Popolo, J. A. (1960). Experiences a student teacher should have. Journal of Teacher Education, 11(1), 75-78. 
DeMarrais, K. (2004). Qualitative interview studies: Learning through experience. In K. deMarrais \& S. D. Lapan (Eds.), Foundation for research (pp. 51-68). Mahwah, NJ: Erlbaum.

Dewey, J. (1897). My pedagogic creed. New York, NY: E. L. Kellogg \& Company.

Dexter, L. A. (1970). Elite and specialized interviewing. Evanston, IL: Northwestern University Press.

Diez, M. E. (2010). It is complicated: unpacking the flow of teacher education's impact on student learning. Journal of Teacher Education, 61(5), 441-450.

DiMaggio, P. J., \& Powell, W. W. (1983). The iron cage revisited: Institutional isomorphism and collective rationality in organizational fields. American Sociological Review, 48(2), 147-160.

Donaldson, M. L. (2009). So long, Lake Wobegon? Using teacher evaluation to raise teacher quality. americanprogress.org.

DuFour, R., DuFour, R., \& Eaker, R. (2008). Revisiting professional learning communities at work: New insights for improving schools. Bloomington, IN: Solution Tree Press.

Dwyer, C. A. (1991). Measurement and research issues in teacher assessment. Educational Psychologist, 26(1), 3-22.

Dwyer, C.A. (1993). Teaching and diversity: Meeting the challenges for innovative teacher assessments. Journal of Teacher Education, 44(2), 119-129.

Dwyer, C. A., \& Villegas, A. M. (1993). Guiding conceptions and assessment principals for The Praxis Series: Professional assessments for beginning teachers. Princeton, NJ: Educational Testing Service.

Edmonds, R. (1979). Effective schools for the urban poor. Educational Leadership, $37(1), 15-18,20-24$.

Elmore, R. F. (2002a). Bridging the gap between standards and achievement: The imperative for professional development in education. Albert Shanker Institute.

Elmore, R. F. (2002b). Hard questions about practice. Educational Leadership, 59(8), 2225.

Elmore, R. F. (2007). School reform from the inside out: Policy, practice, and performance. Cambridge, MA: Harvard Education Press. 
Elmore, R. F., \& McLaughlin. (1983). The federal role in education: Learning from experience. Education and Urban Society, 15(3), 309-330.

Fehn, B., \& Koeppen, K. (1998). Intensive document-based instruction in a social studies methods course and student teachers' attitudes and practice in subsequent field experiences. Theory and Research in Social Education, 26, 461-484.

Fosnot, C. T. (1989). Enquiring teachers enquiring learners: A constructivist approach for teaching. New York, NY: Teachers College Press.

Fullan, M., Cuttress, C., \& Kilcher, A. (2005). 8 forces for leaders of change. National Staff Development Council, 26(4), 54-58, 64.

Gable, R. K. \& Wolf, M. B. (1993). Instrument development in the affective domain: Measuring attitudes and values in corporate and school settings $\left(2^{\text {nd }}\right.$ ed.). Boston, MA: Kluwer Academic.

Glickman, C. D. (1990). Pushing school reform to a new edge: The seven ironies of empowerment. Phi Delta Kappan, 72(1), 68-75.

Glickman, C. D. (1993). Renewing America's schools: A guide for school-based action. San Francisco, CA: Jossey-Bass.

Goddard, R. D., LoGerfo, L., \& Hoy, W. K. (2004). High school accountability: The role of perceived collective efficacy. Educational Policy, 18(3), 403-425.

Goodlad, J. I. (1999). Whither schools of education? Journal of Teacher Education, 50(5), 325-338.

Goodwin, B., Lefkowits, L., Woempner, C., \& Hubbell, E. (2011). The future of schooling: Educating America in 2020. Bloomington, IN: Solution Tree.

Graham, B. (2006). Conditions for successful field experiences: Perceptions of cooperating teachers. Teaching and Teacher Education, 22, 1118-1129.

Greenleaf, R. K. (1977). Servant leadership: A journey into the nature of legitimate power \& greatness. New York, NY: Paulist Press.

Grimmett, P. P., \& Ratzlaff, H. C., (1986). Expectations for the cooperating teacher's role. Journal of Teacher Education, 37(6), 41-50.

Grossman, P. L., \& Richert, A. E. (1988). Unacknowledged knowledge growth: Areexamination of the effects of teacher education. Teaching and Teacher Education, 4, 53-62.

Guba, E. G., \& Lincoln, Y. (1981). Effective evaluation. San Francisco, CA: Jossey-Bass. 
Guyton, E., \& McIntyre, D. J. (1990). Student teaching and school experiences. In W. R. Houston (Ed.), Handbook of research on teacher education (pp. 514-534). New York, NY: Macmillan.

Haefele, D. L. (1993). Evaluating teachers: A call for change. Journal of Personnel Evaluation in Education, 7(1), 21-31.

Hammerness, K., Darling-Hammond, L., \& Bransford, J., with Berliner, D., CochranSmith, M., McDonald, M., \&Zeichner, K. (2005). How teachers learn and develop. In L. Darling-Hammond \& J. Bransford (Eds.). Preparing teachers for a changing world: What teachers should learn and be able to do (pp. 358-389). San Francisco, CA: Jossey-Bass.

Hewson P., Tabachnick R., Zeichner, K., \& Lemberger, J. (1999) Educating prospective teachers of biology: Findings, limitations, and recommendations. Science Education, 83, 373-384.

Hicks, E. P. (1969). Changing the role of the cooperating teacher. Journal of Teacher Education, 20(2), 153-157.

Hiebert, J. Gallimore, J., \& Stigler, J. W. (2002). A knowledge base for the teaching profession: What would it look like and how can we get one? Educational Researcher, 31(5), 3-15.

Hightower, A. H., Delgado, R. C., Lloyd, S. C., Wittenstein, R., Sellers, K., \& Swanson, C. B., (2011). Improving student learning by supporting quality teaching: Key issues, effective strategies. Editorial Projects in Education.

Hollins, E. R. (1995). Revealing the deep meaning of culture in school learning: Framing a new paradigm for teacher preparation. Action in Teacher Education, 17(1), 7079.

Horowitz, F. D., Darling-Hammond, L., \& Bransford, J., with Comer, J., Rosebrock, K., Austin, K., \& Rust, F. (2005). Educating teachers for developmentally appropriate practice. In L. Darling-Hammond \& J. Bransford (Eds.). Preparing teachers for a changing world: What teachers should learn and be able to do (pp. 88-125). San Francisco, CA: Jossey-Bass.

Hoy, W., K., \& Woolfolk, A. E. (1990). Socialization of student teachers. American Educational Research Journal, 27(2), 279-300.

Illinois Administrative School Code. (2004). Ill. Admin. Code ch. 23, §25:620.

Illinois Professional Teaching Standards-Illinois State Board of Education. (n.d.) Accessed April 27, 2009, from http://www.isbe.net/profprep/PDFs/ipts.pdf. 
Illinois State University Teacher Education Center: Clinical Experiences and Certification Processes-Student Teaching. (2005) Accessed April 27, 2009, from http://www.coe.ilstu.edu/teacheredcenter/cecp/student_teaching/.

ISBE proposes new rules including student growth to evaluate teachers/principals. Accessed November 10, 2011, from http://www.isbe.net/news/2011/nov18.htm.

Jensen, E. (1995). Brian-based learning. San Diego, CA: The Brain Store.

Kennedy, M. M. (1999). The role of preservice teacher education. In L. DarlingHammond \& L. Sykes (Eds.). Teaching as the learning profession: Handbook of policy and practice (pp. 54-85). San Francisco, CA: Jossey-Bass.

Kennedy, M. M. (2008). Contributions of qualitative research to research on teacher qualifications. Educational Evaluation and Policy Analysis, 30(4), 344-367.

Knoblauch, D., \& Woolfolk Hoy, A. (2008). Maybe I can teach those kids: The influence of contextual factors on student teachers' efficacy beliefs. Teaching and Teacher Education, 24, 166-179.

Koerner, M. E. (1992). The cooperating teacher: An ambivalent participant in student teaching. Journal of Teacher Education, 43(1), 46-56.

Kowalski, T. J. (2006). The school superintendent: Theory practice, and cases $\left(2^{\text {nd }}\right.$ ed.). Thousand Oaks, CA: SAGE Publications.

Lampert, M. (1985). "How do teachers manage to teach? Perspectives on problems in practice. Harvard Educational Review, 55(2), 178-194.

LeCompte, M. D., \& Preissle, J. (1993). Ethnography and qualitative design in educational research ( $2^{\text {nd }}$ ed.). San Diego, CA: Academic Press.

Lindle, J. C., \& Mawhinney, H. B. (2003). Introduction: School leadership and the politics of education. Educational Administration Quarterly, 39(1), 3-9.

Lingren, V. C. (1957). The certification of cooperating teachers in student teaching programs. Journal of Teacher Education, 8, 403-407.

Lipman-Blumen, J. (1996). Connective leadership: Managing in a changing world. Oxford, UK: Oxford University Press.

Little, J. W. (1990). The persistence of privacy: Autonomy and initiative in teachers' professional relations. Teachers College Record, 91(4), 481-508.

Lortie, D. C. (1975). Schoolteacher ( $2^{\text {nd }}$ ed.). Chicago: The University of Chicago Press. 
Louis, K. S., Marks, H. M., \& Kruse, S. (1996). Teachers' professional community in restructuring schools. American Educational Researcher, 33(4), 757-798.

Martin, S. D., Snow, J. L., \& Franklin Torrez, C. A. (2011). Navigating the terrain of third space: Tensions within relationships in school-university partnerships. Journal of Teacher education, 62(3), 299-311.

Marzano, R. J. (2003). What works in schools: Translating research into action. Alexandria, VA: ASCD.

Marzano, R. J. (2007). The art and science of teaching: A comprehensive framework for instruction. Alexandria, VA: ASCD.

Marzano, R. J., Pickering, D., \& Pollock, J. E. (2001). Classroom instruction that works: Research-based strategies for increasing student achievement. Alexandria, VA: ASCD.

Maxwell, J. C. (1998). The 21 irrefutable laws of leadership: Follow them and people will follow you. Nashville, TN: Thomas Nelson.

Maxwell, J. A. (2004). Causal explanation, qualitative research, and scientific inquiry in education. Educational Researcher, 33(2), 3-11.

McKeag, R. A., Koll, P. J., \& Herzog, B. J. (1978). A cooperative approach to supervising student teachers. NASSP Bulletin, 62(416), 62-67.

Merriam, S. (2009). Qualitative research: A guide to design and implementation. San Francisco, CA: Jossey-Bass.

Moore, R. (2003). Reexamining the field experiences of preservice teachers. Journal of Teacher Education, 54(1), 31-42.

Moustakas, C. (1994). Phenomenological research methods. Thousand Oaks, CA: Sage.

Meyer, J. W., \& Rowan, B. (1977). Institutionalized organizations: Formal structure as myth and ceremony. The American Journal of Psychology, 83(2), 340-363.

Miles, M. B., Huberman, A. M., \& Saldana, J. (2014). Qualitative data analysis: A methods sourcebook ( $3^{\text {rd }}$ ed.). Thousand Oakes, CA: Sage.

Morgan, G. (1986). Images of organization. Newbury Park, CA: Sage Publications.

National Center for Education Statistics. (2013). The nation's report card: Trends in academic progress 2012. NCES 2013-456, National Center for Education Statistics, Institute of Education Sciences, U.S. Department of Education, Washington, DC. 
National Commission on Excellence in Education. (1983). A nation at risk. Washington, DC: United States Government Printing.

National Commission on Teaching \& America's future. (1996). Retrieved from National commission on teaching and America's future website: What matters most:

Teaching for America's future. Retrieved from http://www.nctaf.org/documents/WhatMattersMost.pdf.

Newmann, F. M., Smith, B., Allensworth, E., \& Bryk, A. S. (2001).Instructional program coherence: What it is and why it should guide school improvement. Educational Evaluation and Policy Analysis, 23(4), 297-321.

Oakes, J. (1989). What educational indicators? The case for assessing the school context. Educational Evaluation and Policy Analysis, 11(2), 181-199.

Patton, M. Q. (2002). Qualitative research and evaluation methods ( $3^{\text {rd }}$ ed.). Thousand Oaks, CA: Sage.

Piaget, J. (1976). To understand is to invent: The future of education. New York: Penguin Books.

Powell, A. G. (1985). The shopping mall high school: Winners and losers in the educational marketplace. Boston, MA: Houghton Mifflin Company.

Ravitch, D. (2010). The death and life of the great American school system: How testing and choice are undermining education. Philadelphia, PA: Basic Books.

Richardson-Koehler, V. (1988). Barriers to effective supervision of student teaching. Journal of Teacher Education, 39(2), 28-34.

Rosenholtz, S. J. (1989). Teachers' workplace: The social organization of schools. New York, NY: Longman.

Saldana, J. (2013). The coding manual for qualitative researchers $\left(2^{\text {nd }}\right.$ ed.). Los Angeles, CA: Sage.

Sappington, N., Baker, P., Gardner, D., \& Pacha, J. (2010). A signature pedagogy for leadership education: Preparing principals through participatory action research. Planning and Changing, 41(3/4), 249-273).

Sappington, N., Pacha, J., Baker, P., \& Gardner, D. (2012). The organized contradictions of professional development and school improvement. International Journal of Educational Leadership Preparation, 71(1), 1-12.

Schein, E. H. (2004). Organizational culture and leadership ( $3^{\text {rd }}$ ed.). San Francisco: Jossey-Bass. 
Scherer, M. (2001). How and why standards can improve student achievement: A conversation with Robert J. Marzano. Educational Leadership, 59(1), 14-18.

Selznick, P. (1957). Leadership in administration: a sociological interpretation. Berkeley, CA: University of California Press.

Shulman, L. S. (1974). The psychology of school subjects: A premature obituary? Journal of Research in Science Teaching, 11(4), 319-339.

Shulman, L. S. (1986). Those who understand: Knowledge growth in teaching. Educational Researcher, 15(2), 4-14.

Shulman, L. S. (1987). The wisdom of practice: Managing complexity in medicine and teaching. In D. C. Berliner \& B. V. Rosenshine (Eds.), Talks to Teachers: A festschrift for N. L. Gage (pp. 367-387). New York, NY: Random House.

Shulman, L. S. (2005). Signature pedagogies in the professions. Daedalus 134(3), 52-59.

Shulman, L. S., \& Shulman, J. H. (2008/2009). How and what teachers learn: A shifting perspective. Journal of Education, 189(1/2), 1-8.

Shulman, L. S. (n.d.). No Drive-by teachers. Carnegie Foundation Original Perspectives accessed December 31, 2012, from http://www.carnegiefoundation.org/perspectives/no-drive-teachers.

Spillane, J. P. (2006). Distributed leadership. San Francisco, CA: Jossey-Bass.

Tschannen-Moran, M., Woolfolk Hoy, A., \& Hoy, W. K. (1998). Teacher efficacy: Its meaning and measure. Review of Educational Research, 68(2), 202-248.

Tyack, D. B. (1967). Turning points in American educational history. Waltham, MA: Blaisdell.

Valencia, S. W., Martin, S. D., Place, N. A., \& Grossman, P. (2009). Complex interactions in student teaching: Lost opportunities for learning. Journal of Teacher Education, 60(3), 304-322.

Van Manen, M. (1979). Reclaiming qualitative methods for organizational research: A preface. Administrative Science Quarterly, 24(4), 520-526.

Van Manen, M. (1990). Researching lived experience: Human science for an action sensitive pedagogy. New York, NY: State University of New York.

Weatherly, R., \& Lipsky, M. (1977). Street-level bureaucrats and institutional innovation: implementing special-education reform. Harvard Educational Review, 47(2), 171-197. 
Webber, C. F. (1994). The five elements of successful student teaching. Kappa Delta Pi Record, 30(2), 78-81.

Weick, K. E. (1976). Educational organizations as loosely coupled systems. Administrative Science Quarterly, 21(1), 1-19.

Weick, K. E. (1982). Administering education in loosely coupled schools. Phi Delta Kappan, 63(10), 673-676.

Wilson, S. M., Floden, R. E., \& Ferrini-Mundy, J. (2001). Teacher preparation research: Current knowledge, gaps, and recommendations. Seattle, WA: Center for the Study of Teaching and Policy.

Wineburg, M. S. (2006). Evidence in teacher preparation: Establishing a framework for accountability. Journal of Teacher Education, 57(1), 51-64.

Wright, S. P., Horn, S. P., \& Sanders, W. L. (1997). Teacher and classroom context effects on student achievement. Implications for teacher evaluation. Journal of Personnel Evaluation in Education, 11(1), 57-67.

Yinger, R. J., \& Hendricks-Lee, M. S. (2000). The language of standards and teacher education reform. Educational Policy, 14(1), 94-106.

Zeichner, K. (2010). Rethinking connections between campus courses and field experiences in college- and university-based teacher education. Journal of Teacher Education, 61(1-2), 89-99. 


\section{APPENDIX A}

\section{SAMPLE RECRUITMENT LETTER}

Dear

I am a practicing high school administrator and a doctoral student at Illinois State University and am currently working on my dissertation, a research study exploring the factors perceived relevant in the placement of high school student teachers in Science, Math, or English.

While time is at a premium for all school leaders, research of practices in the field of education is invaluable in continuing to improve the service we all provide to students and their communities.

I am requesting your participation, which will involve one audio-taped interview with me that will take place in a location convenient to you. I expect the interview will last approximately 45-60 minutes. The questions will relate to your thoughts on the factors that are considered in student teacher placements, as well as the process you use for these placements. Your responses will be kept confidential, and pseudonyms will be assigned. Reflecting on one's practice through participation in this type of research can also help individuals reflect on their own educational practices.

Your participation is entirely voluntary and would be greatly appreciated. If you are willing to participate in this research study, please respond to this e-mail with your name and a contact phone number. I will call you within 2-3 days to set up a convenient time for the interview. In case this email does not reach you, I may also make one phone attempt to contact you and request your participation. Please also feel free to contact me if there is any additional information I may provide to help you decide if you're willing to participate in this study.

If you agree to participate in the study but withdraw at any time, there is no penalty of any kind. Thank you, in advance, for considering this request.

Sincerely,

Julie L. Pavlini 


\section{APPENDIX B SAMPLE CONSENT FORM}

Dear

I am a practicing high school administrator and a doctoral student at Illinois State University and am currently working on my dissertation, a research study exploring the factors perceived relevant in the placement of high school student teachers in science, math, or English. The placement of student teachers is at the root of the future success of education, as these placements determine the success of our future teachers.

I am requesting your participation, which will involve one audio-taped interview with me that will take place in a location convenient to you. I expect the interview will last approximately 4560 minutes. The questions will relate to your thoughts on the factors that are considered in student teacher placements, as well as the process you use for these placements.

Your participation is entirely voluntary and is greatly appreciated. If you choose not to participate or to withdraw from the study at any time, there will be no penalty of any kind. Your decision to participate or not to participate will not affect your employment in any way. The results of the research study may be published, but your name will not be used. I will take all precautions to maintain your confidentiality (your name will not be used, and the transcript from our interview will not be shared). For example, pseudonyms will be used during the interview and the final report. You may decline to answer any questions within the study.

Although there may be no direct benefit to you from the study itself, the possible intrinsic benefit of your participation would be to reflect on the student teacher placement process overall and the individual role you play within the field of education.

If you have any questions concerning the research study, please call me at $(\square)-$, or you may contact my study advisor, Dr. Neil Sappington at 309-438-2058.

Sincerely,

Julie L. Pavlini

I give consent to participate in the above study. I understand that my interview will be audiotaped.

Signature

Date

If you have any questions about your rights as a subject/participant in this research, or if you feel you have been placed at risk, you can contact the Research Ethics \& Compliance Office at Illinois State University at (309) 438-2529 and/or rec@ilstu.edu. 


\section{APPENDIX C}

\section{INTERVIEW PROBES}

\section{Introductions \& Building Rapport}

Review information from the previously completed information sheet (Attachment 6). What do you remember about your own student teaching experience?

\section{Primary Interview Probes}

What is the process for placing student teachers?

Who is involved in placing student teachers?

What is the process for selecting cooperating teachers?

Who is involved in selecting cooperating teachers?

Who do you think should be involved in placing student teachers?

Who do you think should be involved in selecting cooperating teachers?

How successful do you consider the student teacher placement process to be?

What are the benefits of having a student teacher?

What are the challenges of having a student teacher?

How are student teachers viewed by students?

How are student teachers viewed by teaching staff/building administrators/district administrators?

What documents are involved in the student teaching process in your district/building? For the purpose of research, would I be able to have sample copies of these documents with identifying information removed?

When you have open positions, what percentage of student teachers is hired?

Describe the evaluations used to assess student teachers?

What is the focus of these evaluations of the student teachers?

Describe the evaluations used to assess cooperating teachers?

What steps does your district/building take to review college and university preparation of student teachers?

\section{Wrap-up}

Is there anything else that you want to add about the topics we've discussed today? If you agreed to provide documents with identifying information removed, may we make arrangements for sharing those documents with me?

If necessary, may I contact you again to follow up on this interview? 


\section{APPENDIX D}

\section{INTERVIEW ACTIVITY \#1}

\section{Choose a Cooperating Teacher (CT)}

Please review the following three fictional descriptions of teachers and identify which you would be most likely to assign a student teacher. Please share your thought process as you make your decision. (What criteria were most important factors for you in selecting the cooperating teacher? What additional pieces of information would be important for you to know in order to make your decision among these three candidates?)

Mr. X, a $6^{\text {th }}$ year teacher who began teaching immediately after graduating from college, has been working at Roosevelt High for 5 years. He has completed 3 university credit hours beyond his BA. During his time at Roosevelt High, he has coached both boys' and girls' volleyball. He currently chairs the school's staff morale committee and has been a building representative with the teacher's association for the past three years. His evaluations for his first 3 years were "Satisfactory"; each of his evaluation rating for the past 3 years has been "Excellent." Mr. X's students describe him as disorganized but cool; students frequently request him as a teacher. No student has ever failed Mr. X's class.

Mrs. Y, a 31-year veteran who began teaching immediately after graduating from college, has been working at Roosevelt High for 12 years. She has 47 university credit hours beyond her MAT. During her time at Roosevelt High, she has written curriculum for multiple courses, including the AP course she currently teaches. Mrs. Y loves teaching and has no plans to retire any time soon. Mrs. Y's honors and AP students are successful; her regular level courses average a 25\% failure rate.

Ms. Z, a 15-year veteran who began teaching after a brief career in advertising, has been working at Roosevelt High for 15 years. She has a BA in advertising and an MAT. During her time at Roosevelt High, she has participated in several district committees and sits on the building school improvement team. Ms. Z frequently volunteers for additional responsibilities outside of the classroom and was recently nominated for the state "High Fliers" Award. Ms. Z's students say she is fun loving and energetic. She is extremely organized and requires students to be the same, frequently repeating her favorite quote: "Failure to plan on your part does not constitute an emergency on my part."

NOTE: The descriptions of the potential cooperating teachers were on separate laminated sheets for the interview activity. 


\section{APPENDIX E \\ INTERVIEW ACTIVITY \#2}

\section{Trait Sort}

Please review the provided list of potential cooperating teacher qualities, and identify the 3 traits you consider to be most important and the 3 traits you consider to be least important in a cooperating teacher. Please share your thought process as you make your decision.

Domain 1

Knowledge of content

Knowledge of content-related pedagogy

Knowledge of students' skills, knowledge and development

Domain 2

Management of student behavior

Management of classroom materials

Domain 3

Communication with students

Engagement of students in learning

Use of formative \& summative assessment to guide instruction

Domain 4

Communication and partnership with families

Participation in professional growth and school improvement

Reflection on teaching practices

NOTE: Traits were not sorted by domains for use during the interview activity. They were in random order on separate laminated strips. 